\title{
LA PRODUCCION Y LA PRODUCTIVIDAD AGRARIA ESPAÑOLAS, 1890-1936
}

JAMES SIMPSON *

Universidad Carlos III de Madrid

\section{RESUMEN}

El artículo tiene tres secciones. En la primera he estudiado los cambios a largo plazo del producto final de la agricultura española entre 1891/13. En la segunda sección, los datos con interpretaciones para regiones de España en 1929/33. Por último muestro los cambios en la productividad de estas regiones entre 1909/13 y 1929/33, la época identificada con el mayor crecimiento en la productividad. El artículo también tiene apéndices con los métodos utilizados para hacer los cálculos y cuadros mostrando los resultados por provincia.

\section{ABSTRACT}

The article is divided into three sections. In the first I examine long term changes in final agricultural output between 1891 and 1936, which indicates that only from $1909 / 13$ did land and labour productivity start to increase. In the second section I present figures for regional productivity in 1929/33, and suggest reasons why some of the major local differences occurred. Finally, I show changes in regional productivity between $1909 / 13$ and $1929 / 33$, the period identified as the one with greatest productivity growth. The article also includes appendices which explain the methods used, and provides Tables showing the results by province.

La considerable dimensión de la rama agraria, tanto en términos de su contribución al producto interior bruto como de su empleo de recursos, hace que resulte crucial el conocimiento de las variaciones en su productividad para comprender la economía española en el período anterior a la Guerra Ci-

* Ayuda recibida de la DGICYT, n. ${ }^{\circ}$ PB90-0268. 
vil. Si bien es cierto que la estimación del incremento en la producción agraria durante el siglo XIX siempre resulta controvertida debido a la escasa calidad de las estadísticas oficiales, las estimaciones desde principios del siglo $\mathrm{xx}$ resultan menos discutibles, ya que se dispone de numerosas estimaciones, con una exactitud dentro de lo razonable, de la superficie cultivada, la producción y los precios de los productos. En la primera sección del artículo presentamos nuevas estimaciones sobre la magnitud de los cambios en la producción y en la productividad del trabajo y de la tierra, para la agricultura española durante los cincuenta años anteriores a la Guerra Civil. Nuestras conclusiones indican que la productividad del trabajo y de la tierra solamente aumentaron de manera significativa a partir de la segunda década del siglo xx. En las secciones segunda y tercera presentamos por primera vez estimaciones detalladas de la producción y la productividad por provincias y regiones. Estos cálculos nos permiten identificar un cierto número de economías agrarias claramente diferenciadas, lo que indica que el atraso en términos internacionales de la rama agraria española, que han puesto de manifiesto recientemente O'Brien y Prados de la Escosura, es complejo y no puede ser explicado por un factor en particular sino por un conjunto de ellos ${ }^{1}$.

\section{EL CRECIMIENTO DE LA PRODUCCION Y LA PRODUCTIVIDAD AGRARIA, 1891-1936²}

La existencia de información anual sobre las superficies cultivadas y la cuantia de las cosechas para el trigo a partir de 1880 , otros cereales, leguminosas, olivos y vides a partir de 1891 y la mayoría de los otros cultivos desde principios del siglo $\mathrm{xx}$, permite que se puedan realizar comentarios pormenorizados sobre la producción y la productividad agraria desde finales del siglo XIX ${ }^{3}$. Sin embargo, para los primeros años de este período, la existencia de una mayor información estadística no ha clarificado el debate sobre la evolución de la producción agraria, ya que las propias fuentes se prestan a interpretaciones conflictivas. En particular, el crecimiento aparente en las cifras oficiales sobre la superficie cultivada y la producción de trigo a partir de 1891, año en que entró en vigor un arancel proteccionista sobre los cereales, se puede

1 Estos aspectos no se abordan aqui, sino en Simpson, de próxima publicación.

2 Cualquier trabajo de este tipo se encuentra en deuda con el articulo pionero del Grupo de Estudios de Historia Rural (GEHR), presentado en el II Congreso de Historia Económica y publicado en 1983.

3 Sobre las fuentes, véase GEHR (1983 y 1991), Sanz (1981) y Simpson (1989). 
explicar como consecuencia de la recuperación tras la «gran depresión», como una mejora en el proceso de recopilación de la información estadística por parte de los organismos oficiales o como una combinación de ambas. Si bien algunos coetáneos no tenian mucha confianza en las estadísticas oficiales, la profundidad, duración y naturaleza de la «gran depresión» en la agricultura no está determinada, de manera definitiva, por los historiadores españoles ${ }^{4}$.

\section{CUADRO 1}

Producción de productos ganaderos 1865-1929/33

(Precios constantes de 1910, millones de pesetas)

\begin{tabular}{|c|c|c|c|}
\hline & (1) & (2) & (3) \\
\hline 1865 & - & 1.156 & 1.156 \\
\hline 1891 & 736 & 716 & 953 \\
\hline 1900 & 589 & 562 & 891 \\
\hline 1910 & 883 & 888 & 1.090 \\
\hline 1921 & 1.190 & - & - \\
\hline 1931 & 1.311 & 1.426 & 1.426 \\
\hline
\end{tabular}

1. GEHR (1983). Apéndice 6 .

2 y 3 . Véase el texto y el Apéndice 1.

Aunque sigan dejando mucho que desear, las estadísticas oficiales de producción, desde principios del siglo $\mathrm{xx}$, son significativamente mejores, tanto en la calidad como en el detalle, y permiten determinar las tendencias generales de la producción'. Con base en estas estadísticas, el GEHR señala que la producción agraria creció un 1,8 por ciento anualmente entre 1900 y $1931^{6}$. Esta

4 Véase, especialmente, Sanz (1981), Garrabou y Sanz (1985), Garrabou et al. (1988) y Simpson (1992a).

5 GEHR (1991). No obstante, en sus estimaciones de la productividad agraria para el sur y el este de Europa para la Sociedad de Naciones en el período 1931-1935, Moore escribe que aen las comparaciones internacionales aparece de forma regular la sobrevaloración de la producción española», y sugiere que puede ser atribuible a una infraestimación del consumo animal de las cosechas y, en parte, también a «estadísticas de producción exageradas», Moore (1945), p. 37. Un estudio reciente que utiliza diferentes cifras de consumo animal, reduce, en cierta medida, las cifras de productividad del trabajo masculino, relativamente elevadas, ofrecidas por Moore. Véase O'Brien y Prados de la Escosura (1992a), cuadro 6.

6 GEHR (1983), p. 229. 
cifra, sin embargo, no es incuestionable. En primer lugar, se refiere a la producción total y el GEHR no efectúa ninguna estimación de la producción neta de productos de reempleo. En segundo lugar, las cifras a precios constantes se han obtenido utilizando la cifra de inflación del conjunto de la economia en vez de utilizar un precio para cada uno de los diferentes productos. Por último, resulta probable que la contribución de la ganadería en 1891 se encuentre subestimada, por lo que la tasa de crecimiento en el medio siglo anterior a la Guerra Civil resulta exagerada. Los dos primeros problemas son relativamente fáciles de resolver, aunque el empleo de coeficientes adecuados a la hora de estimar los productos de reempleo presente sus propios problemas (véase en el Apéndice 1 los métodos que hemos seguido en este trabajo). El problema de la producción ganadera se aborda seguidamente.

Las mejores cifras de los censos ganaderos se refieren a los años 1750 (únicamente para la Corona de Castilla), 1865, 1917, 1929 y $1933^{7}$. Quizá de manera sorprendente, una estimación aproximativa muestra que se produjeron pocos cambios en las cifras globales referidas a los distintos censos, lo que supondría una caida significativa en la producción per cápita de carne, leche y lana ${ }^{8}$. Existen otros censos para los años $1799,1859,1891,1905$, etc.; sin embargo, en éstos se ofrece menos detalle sobre los procedimientos de recopilación de la información, no existe un desglose por municipios (lo que dificulta la realización de contrastes más rigurosos) y, en general, se considera que se construyeron utilizando métodos considerablemente menos cientificos que los empleados en los censos referidos a los años mencionados anteriormente. Estos censos ofrecen también cifras mucho más reducidas. En el cuadro 1 se destaca este problema y se sugieren dos alternativas. La primera columna se refiere al trabajo del GEHR y muestra una caída en la producción ganadera en 1900 con respecto a la ya reducida cifra de 1891 . A partir de ese momento se produce una rápida recuperación, alcanzándose una tasa de crecimiento anual de aproximadamente 2,6 por ciento entre 1910 y 1931. La segunda columna se ha obtenido utilizando las mismas cifras que el GEHR y con métodos relativamente similares, aunque los valores a precios constantes se han estimado basándose en los precios referidos al periodo 1909-1913 para la carne, la leche y la lana. Estas cifras muestran un descenso del 2,1 por ciento anual entre 1865 y 1900, y luego un crecimiento de un 3 por ciento anual entre 1900 y 1931. Por último, en la columna 3 se han efectuado modificaciones importantes para los años 1891, 1900 y 1910. En primer lugar, para 1900 y 1910

7 Sobre una descripción general de las cifras del censo, véase GEHR (1978-9 y 1991), Zapata (1986) y Simpson (1989).

8 Zapata (1986), p. 624, y Simpson (1989). 
se utilizan las cifras globales de ganado bovino, ovino, caprino y porcino del censo de 1917, en vez de la información, menos fiable, de los censos de 1903 y 1908/1912 que utilizaba el GEHR ${ }^{9}$. En segundo lugar, la producción correspondiente a 1891 se ha calculado suponiendo una disminución constante en el valor de la producción entre 1865 y 1900 . Por tanto, en esta nueva estimación la producción muestra un descenso menos acusado entre 1865 y 1900 (un 0,7 por ciento anual) y, por consiguiente, una recuperación menos pronunciada en el periodo posterior a 1900 (un 1,5 por ciento anual)

¿Sobre qué evidencia se sustentan estas nuevas estimaciones? Para el caso de Galicia, Carmona y De la Puente han sostenido de manera convincente que resulta extremadamente improbable que se produjera una disminución en el número de cabezas de ganado bovino entre 1865 y 1891 , tal y como apuntan las cifras del censo ${ }^{10}$. En el resto del país es posible que la roturación de tierras comunes y terrenos de pasto redujera el número de cabezas de ganado, aunque no parece concebible una disminución superior al 18 por ciento tal y como aparece en la columna 3 del cuadro 1. Para el período 1891-1895 y 1897-1901 las estadísticas sobre cultivos indican que la reducción en el número de cabezas de ganado fue probablemente minima. Entre estas fechas, la superficie destinada a avena, cebada y maíz se incrementó en 426 miles de hectáreas, compensando con creces la disminución de 679 miles de hectáreas de pastos de escasa calidad ${ }^{11}$. A la inversa, si se ha producido una estimación a la baja de la superficie destinada a cosechas, entonces el menor crecimiento de la superficie dedicada a plantas forrajeras y cereales panificables supondría una reducción en la destrucción de pastos naturales. Tan sólo una disminución significativa en la producción de forraje, la existencia de epidemias que hubieran afectado al ganado bovino o una caida considerable en la demanda de productos animales podrian justificar un descenso del 20 por ciento, tal y como apuntan las cifras censales de la columna 1 en esta última «década» del siglo ${ }^{12}$. No parece haber sido así, por lo que en nuestros cálculos se utilizan las cifras de la columna 3 , que muestra una caida de un 6,5 por ciento.

${ }^{9}$ El censo de 1905 presenta cifras especialmente bajas, lo que probablemente refleje las condiciones climáticas anormales de ese año. Este hecho no se produjo en 1900. Los coeficientes referentes a las vacas lecheras se han calculado en base al material censal de 1865 y 1929/1933, tal y como se indica en el apéndice. Los precios corresponden a 1900 y 1910.

10 Carmona y De la Puente (1988), p. 195.

11 Estos 676 miles de hectáreas corresponden a la rúbrica «prados, dehesas y montes" que incluye considerables superficies dedicadas a la silvicultura. Como se apunta más adelante, probablemente sólo un tercio de esta cantidad corresponda a pastos.

12 En realidad, 14 años, ya que se emplean los censos de 1891 y 1905. Los precios corresponden a 1893 y 1900 . Véase GEHR (1983). 


\section{CUADRO 2}

Producción agraria final en España 1891-1895 y 1929-1933

(Neta de productos de reempleo)

\begin{tabular}{|c|c|c|c|c|c|c|c|}
\hline & \multicolumn{4}{|c|}{ Millones de pesetas de 1909.1913} & \multicolumn{3}{|c|}{$\%$ del total } \\
\hline & $1891 / 95$ & $1897 / 01$ & $1909 / 13$ & $1929 / 33$ & $1897 / 01$ & $1909 / 13$ & $1929 / 33$ \\
\hline Cereales & 788 & 964 & 1.139 & 1.303 & & & \\
\hline Leguminosas. & 103 & 104 & 107 & 124 & & & \\
\hline Subtotal & 891 & 1.068 & 1.246 & 1.427 & $32,3 \%$ & $33,9 \%$ & $30,1 \%$ \\
\hline$\ldots \ldots$ & 525 & 435 & 323 & 484 & $13,1 \%$ & $8,8 \%$ & $10,2 \%$ \\
\hline Olivar ............ & 270 & 270 & 254 & 409 & $8,2 \%$ & $6,9 \%$ & $8,6 \%$ \\
\hline Frutas . . . . . . . & & 167 & 230 & 250 & $5,0 \%$ & $5,4 \%$ & $5,3 \%$ \\
\hline Hortalizas . . . . . . & & 392 & 464 & 610 & $11,9 \%$ & $12,6 \%$ & $12,9 \%$ \\
\hline Plantas industriales . . . . & & 85 & 103 & 135 & $2,6 \%$ & $2,8 \%$ & $2,8 \%$ \\
\hline Subtotal $\ldots \ldots \ldots$ & & 2.417 & 2.620 & 3.315 & $73,1 \%$ & $70,4 \%$ & $69,9 \%$ \\
\hline Productos ganaderos . . . & 953 & 891 & 1.090 & 1.426 & $26,9 \%$ & $29,6 \%$ & $30,1 \%$ \\
\hline TOTAL & & 3.308 & 3.710 & 4.741 & 100,0 & 100,0 & 100,0 \\
\hline
\end{tabular}

FuENTE: Apéndice 1.E.

Con las nuevas cifras sobre productos ganaderos se puede obtener una estimación del crecimiento del producto agrario. La variable escogida para representar este incremento es la producción total neta de productos intermedios ${ }^{13}$. Los resultados indican que en el primer tercio del siglo $\mathrm{XX}$ se produjo un aumento considerable de la producción, pasando ésta de ser 3.308 millones de pesetas en 1897-1901 a 4.741 millones en 1929-1933 (Cuadro 2). Este incremento supone un crecimiento del 1,13 por ciento, desarrollándose el sector ganadero considerablemente por encima del resto (1,48 por ciento frente a un 0,99 por ciento). El crecimiento de la producción fue más elevado entre 1909 . 1913 y 1929-1933 (un 1,23 por ciento) que el que se produjo con anterioridad a la Primera Guerra Mundial (0,96 por ciento) y se dividió aproximadamente en partes iguales entre los cultivos y la ganadería ${ }^{14}$. Es quizá sorprendente que la importancia relativa de los cultivos mediterráneos tradicionales (rotacio-

13 En esencia, la producción total neta del consumo de piensos y plantas forrajeras y la siembra. Veáse apéndice 1.E para los métodos utilizados.

$141897 / 1901 \cdot 1909 / 1913$ : la producción agricola, 0,67 por ciento; la producción ganadera, 1,69 por ciento; el producto agrario, 0,96 por ciento. 1909/1913-1929/1933: la producción agricola, 1,20 por ciento; la producción ganadera, 1,35 por ciento; el producto agrario, 1,23 por ciento. 
nes de cereal-leguminosas, vid y olivo) decayera muy lentamente. De un 53,6 por ciento de la producción en 1897-1901 a alrededor del 48,9 por ciento sólo treinta años después. La producción conjunta de «otros cultivos» - frutales, plantas industriales y plantas hortícolas - permaneció estabilizada aproximadamente en la quinta parte de la producción, mientras que los productos ganaderos aumentaron su proporción en el total hasta sobrepasar el 30 por ciento de la producción ${ }^{15}$.

El crecimiento del producto agrario se puede obtener a través de dos formas diferentes, bien mediante el aumento de la superficie cultivada, bien obteniendo una mayor producción por unidad de terreno, ya sea elevando el rendimiento de los cultivos o mediante un cambio en la composición, pasando de productos con menor valor a productos con mayor valor. El cuadro 3 indica que el incremento de la producción se obtuvo, en parte, como consecuencia del crecimiento de la superficie cultivada. Este factor supuso un 28,7 por ciento del total. En realidad, estas cifras ocultan un aumento de la productividad, ya que en España no habia oferta de tierra elástica de igual calidad a la cultivada en el período 1897-1901. El resto del crecimiento viene explicado por cambios en la composición de los cultivos y en los métodos de producción. En gran medida, los campesinos españoles incrementaron la producción elevando la superficie cultivada (75,9 por ciento), lo que suponía no sólo roturar nuevas tierras; sino reducir las tierras en barbecho, que pasaron de un 44,5 por ciento de la rotación de cereales en 1897-1901 a un 41 por ciento en 1929-193316. La mayor intensidad de cultivo se obtuvo, por lo menos en cierta medida, como consecuencia de la creciente utilización de fertilizantes y de una mejor maquinaria agricola. Por último, el 24,1 por ciento restante viene explicado por otros factores, como el paso a cultivos más rentables y el empleo de métodos de cultivo más eficientes para aumentar la producción.

El principal problema a la hora de estimar la productividad total de la tierra es determinar la superficie que se debe tener en cuenta, ya que es probable que la práctica totalidad del suelo español tuviera algún valor económico, aun-

15 La distribución, incluyendo los productos intermedios, es:

\begin{tabular}{|c|c|c|}
\hline & $1897-1901$ & $1929-1933$ \\
\hline Cultivos tradicionales & $60,7 \%$ & $55,6 \%$ \\
\hline Otros cultivos. & $18,8 \%$ & $22,4 \%$ \\
\hline Ganaderia & $20,5 \%$ & $21,9 \%$ \\
\hline
\end{tabular}

FUENTE: Apéndice 1.C Los pastos y la silvicultura se ban excluido.

16 La exactitud de estas cifras ha de ser cuestionada, ya que en 1960 la cifra era todavia del 41 por ciento. Ministerio de Agricultura, Pesca y Alimentación, (1980), p. 27. 
que proporcionara a una sola cabra una comida al año. En concreto, el problema se centra en la interpretación de la categoría de prados, dehesas y montes, que alcanzó 21.976 miles de hectáreas en 1929-1933. En 1973, cuando datos mas fiables y detallados son disponibles, esta categoría esta dividida en pastizales $(29,3 \%)$, monte maderable $(29,8 \%)$, monte abierto $(22,1 \%)$ y monte leñoso $(18,5 \%)$ y hemos supuesto que la parte dedicada a pastizales era parecida en periodos anteriores, y se incluye en la superficie agraria total ${ }^{17}$.

\section{CUADRO 3}

Causas del incremento de la producción

\begin{tabular}{|c|c|c|c|c|c|c|}
\hline & \multicolumn{3}{|c|}{$\begin{array}{l}\text { Superficie cultivada } \\
\text { miles de hectáreas }\end{array}$} & \multicolumn{3}{|c|}{ Tasas de crecimiento anuales } \\
\hline & $1897 / 01$ & $1909 / 13$ & $1929 / 33$ & $1929 / 33$ & $1909 / 33$ & $1929 / 33$ \\
\hline Sembrada & 11.724 & 12.903 & 15.385 & 0,85 & 0,80 & 0,88 \\
\hline Barbecho & 6.101 & 6.247 & 6.591 & 0,24 & & \\
\hline Pastos ...... & 8.073 & 7.683 & 6.591 & $-0,64$ & $-0,41$ & $-0,77$ \\
\hline Total . & 25.898 & 26.832 & 28.567 & 0,31 & 0,30 & 0,31 \\
\hline \multicolumn{7}{|c|}{ Cambio en la producción total en millones de pesetas (precios de 1910) } \\
\hline Sembrada . & 3.764 & 4.260 & 5.314 & 1,08 & 1,04 & 1,11 \\
\hline Barbecho $\ldots \ldots \ldots \ldots \ldots \ldots$ & 17 & 17 & 18 & 0,18 & & \\
\hline Total & 4.672 & 5.367 & 6.758 & 1,12 & 1,16 & 1,16 \\
\hline
\end{tabular}

$1897-1901$ y $1929-1933$

1. Crecimiento de la superficie cultivada $27,6 \%$

2. Crecimiento de la superficie sembrada $73,9 \%$

3. Otros factores $24,1 \%$

FUENTES: Véanse los apendices 1.a and 1.C. Para los pastos, véase abajo.

De la misma forma, las cifras de población activa en España, al igual que en la mayoria de los paises en esta época, plantean problemas de interpretación que introducen errores a la hora de medir la productividad del trabajo.

17 lbíd., p. 27. Incluso de esta forma se infravalora la superficie total, ya que los montes com. prenden, con frecuencia, zonas temporales de pasto. No obstante, la superficie más importante de tierra se incluye y resulta ser mas comparable con otros paises que si se incluyera la superficie nacional total excluyendo las zonas no agrarias, como las zonas urbanas, los rios, etc. 
La primera dificultad viene motivada por la necesidad de adscribir a cada ocupado a una única actividad dentro de las contempladas en el censo, a pesar de que una característica esencial de una economía poco desarrollada sea el reducido grado de especialización laboral. Por lo tanto, al menos en teoría, si la población en la agricultura pasa de representar dos terceras partes del total a un tercio de la población ocupada en una economia en un determinado periodo, esta disminución, que en apariencia es significativa, puede resultar ser en realidad considerablemente menos importante si en un primer momento la población dedica, digamos, un 45 por ciento del tiempo de trabajo a otros sectores (transporte, industria rural, minería) y si, a la postre, la población que en un principio se encontraba en otros sectores trabaja un número significativo de días en la agricultura (especialmente en la época de la cosecha). La posibilidad de que este suceso aconteciera no significa que se diera en España en el período de nuestro estudio. No obstante, una reflexión sobre el material censal apunta que existen algunas preguntas sin responder. Según las cifras censales, el número de varones empleados en la agricultura creció lentamente, pasando de 4 a 4,7 millones entre 1887 y 1910 , lo que supone un 72 por ciento de la población activa. Entre 1910 y 1930 las cifras disminuyeron en términos absolutos un 18 por ciento, y en esta última fecha el sector representaba tan sólo el 51 por ciento de la población activa ${ }^{18}$. La pregunta relevante es si estas cifras reflejan con exactitud la evolución de la población ocupada en el campo. Hay dos hechos que indican que este ritmo de caida se encuentra sesgado al alza y que podria distorsionar las cifras de productividad del trabajo que ofrecemos más adelante.

En primer lugar, si la población activa se mantuvo estable durante el siglo $\mathrm{XIX}$, podemos suponer también que el crecimiento urbano sería lento ${ }^{19}$. Sin embargo, Reher ha estimado que mientras en 1787 solamente un 13 por ciento de la población vivía en núcleos urbanos, en 1910 la cifra se incrementó hasta alcanzar el 24 por ciento, y la población urbana creció dos veces y medio más que la rural 20 .

Otro posible error aparece en el censo de 1930. Si bien el grado de detalle era considerablemente mayor que en censos anteriores y se recogía un total de

18 Calculado a partir de Nicolau (1989), p. 78.

19 Para una cifra constante de la población activa en el sector agrario, véase Pérez Moreda (1985), pp. 52-54. En ausencia de cifras censales, algunos historiadores han pasado a utilizar el grado de urbanización para ilustrar los cambios intersectoriales en la población activa, notablemente Wrigley (1985) y Persson (1991).

20 Un 1,04 por ciento anual frente a un 0,42 por ciento en el campo, calculado de Reher, 1989 , p. 196. Son consideradas ciudades las capitales de provincia y los núcleos urbanos de más de 20.000 habitantes 
129 ocupaciones y actividades, es precisamente este mayor detalle lo que hace albergar ciertas dudas sobre su calidad, ya que el subgrupo XV de industrias varias agrupa algo más de un millón de ocupados varones, lo que supone la séptima parte del total. Resulta claro que esta categoría incluia ocupaciones desconocidas o que no tenían cabida en otros grupos y que buena parte pertenecian con casi total seguridad a la rama agraria.

\section{CUADRO 4}

Cambios en la productividad

\begin{tabular}{|c|c|c|c|c|c|c|c|}
\hline & \multicolumn{4}{|c|}{ Productividad del trabajo } & \multicolumn{3}{|c|}{ Productividad de la tierra } \\
\hline & (1) & (2) & (3) & (4) & (5) & (6) & (7) \\
\hline $1891 / 5$ & 3.299 * & 4.033 & 818 & 109 & 23.934 * & 138 & 109 \\
\hline $1897 / 01$ & 3.308 & 4.392 & 753 & 100 & 25.898 & 127 & 100 \\
\hline $1909 / 13$ & 3.710 & 4.680 & 793 & 105 & 26.832 & 138 & 109 \\
\hline $1929 / 33$ & 4.741 & 3.827 & 1.239 & 165 & 28.567 & 166 & 131 \\
\hline
\end{tabular}

1. Producción final a precios de 1910 , millones de pesetas.

2. Número de trabajadores agricolas varones (en miles) según los censos de 1887, 1900, 1910 y 1930.

3. Producción por trabajador varón.

4. Indice de productividad del trabajo 1897-1901 - 100 .

5. Tierra de uso agrario, miles de hectáreas.

6. Producción por hectárea, pesetas.

7. Indice de productividad de la tierra 1897-1901 - 100 .

* Se utiliza la hipótesis de que las hortalizas, las frutas y las plantas industriales representaban el 20 por ciento de la producción, como se apunta para otros años en el cuadro 2, y que la superficie de estos cultivos representaba el 7,5 por ciento de la tierra cultivada, al igual que en el periodo 1897-1901.

Fuentes: Para la población activa, cuadro 2 y Nicolau (1989). Para la tierra de uso agrario (véase el texto).

Existen dos problemas adicionales interrelacionados. El primero se refiere a la población activa femenina que, por ejemplo, parece suponer tan sólo al 7 por ciento de los ocupados según el censo de 1930. Las acusadas diferencias entre regiones parecen apuntar a que la participación femenina se encontraba determinada por la dimensión de la finca (pequeña), el tipo de explotación (dedicada a productos lácteos) y el clima (precipitaciones abundantes). No obstante, resulta evidente a partir de diversas fuentes que las mujeres desempeñaron un papel fundamental en la agricultura en todo el pais, permitiendo 
un incremento significativo de la oferta de trabajo en los periodos de alta demanda como el de cosecha. En segundo lugar, el subempleo y el trabajo excedentario son relevantes, ya que la ocupación de los campesinos era mas eleva$\mathrm{da}$ en algunas regiones y años que en otros. En general, el empleo del factor trabajo era mayor cuando se utilizaba trabajo familiar en vez de trabajo asalariado; por tanto si la productividad del trabajo debe medir la producción por hora trabajada entonces resulta preciso corregir las estadísticas oficiales ${ }^{21}$. En este artículo hemos rechazado esta opción dadas las dificultades considerables de medir las horas de trabajo, y por tanto, en el cuadro 4 se ha seguido la pauta convencional y sólo se han utilizado cifras de empleo masculino.

Los resultados que se presentan en el cuadro 4 ilustran una vez más las dificultades de interpretación del crecimiento agrario español en el periodo anterior a la Primera Guerra Mundial. La leve disminución de la productividad del trabajo y de la tierra entre 1891-1895 y 1897-1901 sería mayor si, tal y como se ha apuntado con anterioridad, las cifras publicadas para principios de la década de 1890 se encontrasen sesgadas a la baja. La causa del declive se puede atribuir a la mayor superficie de viñedos improductivos como consecuencia de la filoxera y a un pequeño descenso en la producción ganadera (Apéndice 1.A y 1.E). Parte, aunque no la totalidad, de esta caída se recupera entre 1897-1901 y 1909-1913. La imagen general del período $1891-1895$ y 1909-1913, por tanto, es la de un estancamiento en la productividad del trabajo y de la tierra 22 . Entre $1909-1913$ y $1929-1933$ se produce un crecimiento de la productividad laboral y de la tierra, aunque la productividad de la tierra prácticamente crece el doble que la productividad del trabajo ${ }^{23}$. No obstante, una vez más, se han de tener las debidas cautelas sobre la fecha de este crecimiento, ya que la mitad está motivado por la reducción en el número de campesinos entre $1910 \mathrm{y}$ 1930. Si la caida de la población ocupada en la agricultura hubiera sido más gradual, produciéndose por ejemplo a la misma tasa que la urbanización, en-

${ }^{21}$ Véase O'Brien y Toniolo (1991) si se desean consultar mediciones de trabajo equivalente para el Reino Unido e Italia.

22 Esta descripción es acorde con la del GEHR, aunque los métodos que se han empleado para obtener las cifras son considerablemente diferentes (1983, cuadro 15). Estiman un crecimiento de la producción (que incluye productos intermedios) del 0,2 por ciento, de variaciones en la superficie cultivada del 0,1 por ciento y en la población agraria activa del 0,8 por ciento. Nuestras cifras indican un crecimiento de la producción (excluyendo productos intermedios) del 0,7 por ciento, y de la superficie cultivada del 0,6 por ciento y del trabajo del 0,8 por ciento. Gallego (1986), pp. 1041-1042, apunta una cifra del 28 por ciento para el crecimiento de la producción agraria a precios constantes de 1910 entre 1891-1895 y 1910, y Prados de la Escosura (1988), pp. 127-128, del 24 por ciento entre 1886-1895 y 1903-1912. En estos casos, el Apéndice 1.C recoge un crecimiento del 9,5 por ciento entre $1891-1895$ y $1909-1913$.

23 Ambas cifras se encuentran ligeramente por debajo de las del GEHR. 
129 ocupaciones y actividades, es precisamente este mayor detalle lo que hace albergar ciertas dudas sobre su calidad, ya que el subgrupo XV de industrias varias agrupa algo más de un millón de ocupados varones, lo que supone la séptima parte del total. Resulta claro que esta categoría incluia ocupaciones desconocidas o que no tenian cabida en otros grupos y que buena parte pertenecian con casi total seguridad a la rama agraria.

\section{CUADRO 4}

\section{Cambios en la productividad}

\begin{tabular}{|c|c|c|c|c|c|c|c|}
\hline & \multicolumn{4}{|c|}{ Productividad del trabajo } & \multicolumn{3}{|c|}{ Productividad de la tierra } \\
\hline & (1) & $(2)$ & (3) & (4) & (5) & (6) & (7) \\
\hline $1891 / 5$ & 3.299 * & 4.033 & 818 & 109 & $23.934^{\star}$ & 138 & 109 \\
\hline $1897 / 01$ & 3.308 & 4.392 & 753 & 100 & 25.898 & 127 & 100 \\
\hline $1909 / 13$ & 3.710 & 4.680 & 793 & 105 & 26.832 & 138 & 109 \\
\hline $1929 / 33$ & 4.741 & 3.827 & 1.239 & 165 & 28.567 & 166 & 131 \\
\hline
\end{tabular}

1. Producción final a precios de 1910 , millones de pesetas. y 1930

2. Número de trabajadores agricolas varones (en miles) según los censos de 1887, 1900, 1910

3. Producción por trabajador varón.

4. Indice de productividad del trabajo 1897-1901- 100.

5. Tierra de uso agrario, miles de hectáreas.

6. Producción por hectárea, pesetas.

7. Indice de productividad de la tierra 1897-1901 - 100 .

* Se utiliza la hipótesis de que las hortalizas, las frutas y las plantas industriales representaban el 20 por ciento de la producción, como se apunta para otros años en el cuadro 2 , y que la superficie de estos cultivos representaba el 7,5 por ciento de la tierra cultivada, al igual que en el periodo 1897-1901.

Fuentes: Para la población activa, cuadro 2 y Nicolau (1989). Para la tierra de uso agrario (véase el texto).

Existen dos problemas adicionales interrelacionados. El primero se refiere a la población activa femenina que, por ejemplo, parece suponer tan sólo al 7 por ciento de los ocupados según el censo de 1930. Las acusadas diferencias entre regiones parecen apuntar a que la participación femenina se encontraba determinada por la dimensión de la finca (pequeña), el tipo de explotación (dedicada a productos lácteos) y el clima (precipitaciones abundantes). No obstante, resulta evidente a partir de diversas fuentes que las mujeres desempeñaron un papel fundamental en la agricultura en todo el pais, permitiendo 
un incremento significativo de la oferta de trabajo en los periodos de alta demanda como el de cosecha. En segundo lugar, el subempleo y el trabajo excedentario son relevantes, ya que la ocupación de los campesinos era mas eleva$\mathrm{da}$ en algunas regiones y años que en otros. En general, el empleo del factor trabajo era mayor cuando se utilizaba trabajo familiar en vez de trabajo asalariado; por tanto si la productividad del trabajo debe medir la producción por hora trabajada entonces resulta preciso corregir las estadísticas oficiales ${ }^{21}$. En este artículo hemos rechazado esta opción dadas las dificultades considerables de medir las horas de trabajo, y por tanto, en el cuadro 4 se ha seguido la pauta convencional y sólo se han utilizado cifras de empleo masculino.

Los resultados que se presentan en el cuadro 4 ilustran una vez más las dificultades de interpretación del crecimiento agrario español en el periodo anterior a la Primera Guerra Mundial. La leve disminución de la productividad del trabajo y de la tierra entre 1891-1895 y 1897-1901 sería mayor si, tal y como se ha apuntado con anterioridad, las cifras publicadas para principios de la década de 1890 se encontrasen sesgadas a la baja. La causa del declive se puede atribuir a la mayor superficie de viñedos improductivos como consecuencia de la filoxera y a un pequeño descenso en la producción ganadera (Apéndice 1.A y 1.E). Parte, aunque no la totalidad, de esta caída se recupera entre $1897-1901$ y 1909-1913. La imagen general del período $1891-1895$ y 1909-1913, por tanto, es la de un estancamiento en la productividad del trabajo y de la tierra ${ }^{22}$. Entre $1909-1913$ y $1929-1933$ se produce un crecimiento de la productividad laboral y de la tierra, aunque la productividad de la tierra prácticamente crece el doble que la productividad del trabajo ${ }^{23}$. No obstante, una vez más, se han de tener las debidas cautelas sobre la fecha de este crecimiento, ya que la mitad está motivado por la reducción en el número de campesinos entre 1910 y 1930. Si la caida de la población ocupada en la agricultura hubiera sido más gradual, produciéndose por ejemplo a la misma tasa que la urbanización, en-

21 Véase O'Brien y Toniolo (1991) si se desean consultar mediciones de trabajo equivalente para el Reino Unido e Italia.

22 Esta descripción es acorde con la del GEHR, aunque los métodos que se han empleado para obtener las cifras son considerablemente diferentes (1983, cuadro 15). Estiman un crecimiento de la producción (que incluye productos intermedios) del 0,2 por ciento, de variaciones en la superficie cultivada del 0,1 por ciento y en la población agraria activa del 0,8 por ciento. Nuestras cifras indican un crecimiento de la producción (excluyendo productos intermedios) del 0,7 por ciento, y de la superficie cultivada del 0,6 por ciento y del trabajo del 0,8 por ciento. Gallego (1986), pp. 1041-1042, apunta una cifra del 28 por ciento para el crecimiento de la producción agraria a precios constantes de 1910 entre $1891-1895$ y 1910, y Prados de la Escosura (1988), pp. 127-128, del 24 por ciento entre 1886-1895 y 1903-1912. En estos casos, el Apéndice 1.C recoge un crecimiento del 9,5 por ciento entre $1891-1895$ y $1909-1913$.

${ }_{23}$ Ambas cifras se encuentran ligeramente por debajo de las del GEHR. 
tonces la productividad del trabajo comenzaría a crecer más tarde y la caída entre $1891-1895$ y $1897-1901$ sería despreciable ${ }^{24}$.

\section{LA PRODUCCION Y LA PRODUCTIVIDAD REGIONAL}

Las dificultades que se encuentran a la hora de reconstruir series regionales o provinciales son todavia mayores que cuando se desea construir series a nivel nacional ${ }^{25}$. Sin embargo, el hecho de que exista suficiente información estadistica referente a los comienzos del siglo xx para España y que las cifras nacionales sean en realidad la mera suma de las estimaciones provinciales son razones que hacen pensar que un estudio pormenorizado es factible y necesario. Presentamos por vez primera un desglose regional pormenorizado de la producción neta de reempleos (la producción final agraria) a partir de la cual estimamos la productividad de la tierra y del trabajo con anterioridad a la Guerra Civil. En este apartado nos referimos únicamente a los resultados y remitimos al lector interesado al Apéndice 2 para encontrar los detalles por provincias, los coeficientes empleados en las conversiones y las fuentes utilizadas.

Teniendo en cuenta la diversidad geográfica de numerosas provincias, cualquier división de España en diferentes zonas agrícolas resulta inevitablemente controvertida ${ }^{26}$. En este apartado dividimos el país en cuatro regiones: el norte (Galicia, Asturias, Santander y las dos provincias marítimas del Pais Vasco - Guipúzcoa y Vizcaya-); la zona mediterránea (Cataluña exceptuando Lleida, las islas Baleares, el Pais Valenciano y Murcia); Andalucia (las ocho provincias) y el resto, que denominamos Interior.

Históricamente, la zona mediterránea ha sido señalada como la más dinámica de las regiones agricolas españolas, especialmente por Vilar, que hizo hincapié en la importante contribución de la agricultura catalana a la industrialización de la región en la segunda mitad del siglo xviII ${ }^{27}$. Recientemente se ha

${ }^{24} \mathrm{Si}$ tomamos 1897-1901 como base 100, el indice es 102 para 1891-1895, 113 para 1909. 1913 y 155 para 1929-1933. El tamaño de la población ocupada en la agricultura se calcula que creció entre 1887 y 1930 a la misma tasa que la urbanización, medida utilizando ciudades de 10.000 o más habitantes. Estimaciones a partir de Luna (1988).

25 Por ejemplo, en su estudio referido a las economías europeas para el periodo 1931-1935, Moore encuentra que la producción per cápita para Inglaterra y el Pais de Gales muestra cuna posíción superior para el País de Gales y el suroeste de Inglaterra que para el este y el sudoeste. Una comprobación rigurosa de las estadísticas oficiales y ciertas pruebas con las ratios de precios nacionales no ofreció ninguna explicación de este resultado sorprendente», Moore (1945), p. 39.

26 La unidad estadística más pequeña disponible es la provincia, salvo en 1917 y 1922, para cuando se dispone de cierta información según los partidos judiciales.

27 Vilar (1962). 
observado la diversificación y la inversión productiva relativamente intensa en la agricultura y en las industrias afines en Valencia desde finales del siglo XIX ${ }^{28}$. Por contra, para el resto del país se suele hablar de los factores climáticos e institucionales como frenos. En el cuadro 5 no se contradicen necesaria. mente estas observaciones, porque lo importante para el desarrollo económico es el valor añadido en el sector, los niveles de exportación y los enlaces hacia adelante y atrás a otros sectores de la economía. Si hubiera existido una agricultura más dinámica en la zona mediterránea su influencia sobre la economía nacional, a diferencia de la economia regional, hubiera quedado limitada debido a su reducido tamaño. En los primeros años de la Segunda República la contribución de esta zona era ligeramente inferior a la de las regiones habitualmente consideradas como «atrasadas», como Andalucía o el norte ${ }^{29}$. El cuadro 5 muestra que el Interior y Andalucia representaban cuatro quintos de la tierra de uso agrario, aunque la producción por hectárea era de sólo un tercio y la productividad del trabajo tres cuartas partes de las otras dos regiones, a saber, el norte y la zona mediterránea, en 1929-1933. Consideramos ahora las causas de las diferencias regionales en la productividad de la tierra y del trabajo con mayor detalle.

\section{CUADRO 5}

Producción y productividad regionales en la agricultura española, 1929-1933

\begin{tabular}{lcccc}
\hline & $\begin{array}{c}\text { \% dela } \\
\text { superficie } \\
\text { agricola }\end{array}$ & $\begin{array}{c}\text { \% dela } \\
\text { producción } \\
\text { nacional }\end{array}$ & $\begin{array}{c}\text { Producción } \\
\text { por bectárea } \\
\text { en pesetas }\end{array}$ & $\begin{array}{c}\text { Producción } \\
\text { por trabajador } \\
\text { varón } \\
\text { en pesetas }\end{array}$ \\
\hline Norte $\ldots \ldots \ldots \ldots \ldots \ldots \ldots \ldots \ldots \ldots \ldots$ & 7,3 & 18,5 & 809 & 2.750 \\
Interior $\ldots \ldots \ldots \ldots \ldots \ldots \ldots \ldots \ldots \ldots \ldots$ & 62,6 & 42,1 & 216 & 2.326 \\
Andalucía $\ldots \ldots \ldots \ldots \ldots \ldots \ldots \ldots \ldots$ & 19,1 & 17,1 & 288 & 1.630 \\
Mediterránea $\ldots \ldots \ldots \ldots \ldots \ldots \ldots \ldots$ & 11,0 & 22,3 & 650 & 2.688 \\
España ............................... & 100,0 & 100,0 & 327 * & 2315 *
\end{tabular}

* Incluye las islas Canarias.

FuENTE: Véase el Apéndice 2.

${ }_{28}$ Garrabou (1985), Palafox (1985), Piqueras (1985) y Nadal (1990).

29 Cataluña (Barcelona, Gerona, Lérida y Tarragona) aportó el 8,7 por ciento de la producción final, la productividad del trabajo era de 2.439 pesetas por trabajador varón y la producción por hectárea era de 605 pesetas. El País Valenciano (Alicante, Castellón y Valencia) produjo el 10,9 por ciento, la productividad del trabajo era de 2.987 pesetas y la productividad de la tierra era 905 pesetas. 


\section{2a. La producción por hectárea}

Si bien la calidad de la tierra era considerablemente variada en España, la intensidad y la combinación de cosechas antes de 1936 se encontraban determinadas por la presencia de sequías estivales. El cuadro 6 indica que la producción en el Interior y Andalucia se centraba fundamentalmente en cereales, leguminosas, olivos y vides, cultivos éstos típicos de zonas con precipitaciones escasas e irregulares. Cualquier ventaja comparativa de la que disfrutasen estas regiones no era consecuencia de los rendimientos, que se encontraban poco por encima de la media nacional y que, en el caso de los cereales, necesitaban rotaciones extensivas.

\section{CUADRO 6}

Composición de la agricultura por regiones, 1929-1933

\begin{tabular}{lccccc}
\hline & Cereales & $\begin{array}{c}\text { Vides } \\
\text { yolivos }\end{array}$ & $\begin{array}{c}\text { Otros } \\
\text { cultivos }\end{array}$ & Ganaderia & $\begin{array}{c}\text { Hectáreas por } \\
\text { trabajador } \\
\text { varón }\end{array}$ \\
\hline Norte $\ldots \ldots \ldots \ldots \ldots \ldots$ & 16,8 & 2,6 & 26,7 & 53,9 & 3,4 \\
Interior .............. & 41,0 & 13,2 & 23,7 & 22,2 & 10,8 \\
Andalucia ............. & 28,4 & 27,5 & 23,6 & 20,5 & 5,7 \\
Mediterránea ......... & 15,5 & 17,3 & 48,5 & 18,7 & 4,1 \\
España ............... & 28,0 & 14,3 & 31,0 & 26,7 & 7,1 \\
\hline
\end{tabular}

* Se incluye en el total las islas Canarias.

Fuente: Apéndice 2.

Por contra, la producción por hectárea era considerablemente más elevada en el norte y en la zona mediterránea, lo que se puede explicar por las condiciones más favorables para la ganadería estante (en el norte) y por los cultivos intensivos, especialmente frutas, hortalizas y frutos secos (en la zona mediterránea - «otros cultivos», en el cuadro 6). La ganadería intensiva no era sencilla, fuera de la región norte, debido al elevado coste de los pastos y forrajes como consecuencia de las sequías estivales. La zona mediterránea aprovechaba el regadio que permitía el cultivo de frutas y la horticultura. Estas dos regiones, que en el periodo 1929-1933 tan sólo ocupaban el 18 por ciento de la tierra 
de uso agrario del país, producian el 55 por ciento de la producción nacional de frutas, hortalizas y frutos secos ${ }^{30}$.

El segundo factor era el tamaño de la explotación. Los coetáneos observaron con frecuencia la elevada producción por hectárea de los minifundios de explotación familiar respecto a los latifundios que empleaban trabajo asalariado. La reducida superficie de tierras de calidad (bien sean de regadio en la zona mediterránea o de cultivo en el norte), junto con el crecimiento demográfico, traían consigo rentas elevadas, por lo que la única alternativa disponible para los campesinos era el cultivo intensivo de los minifundios. Las elevadas rentas de la tierra reducian los beneficios de las explotaciones, con la consiguiente repercusión sobre la inversión y el consumo personal. No obstante, el cuadro 6 apunta que el cultivo intensivo resultaba ser una forma de reducir los riesgos. La complejidad de las rotaciones en el norte y en las tierras de regadío de la zona mediterránea permitía a los campesinos aprovecharse tanto de una mayor variedad de productos como de rendimientos más elevados y estables. Además, en las zonas costeras donde la demanda externa permitió la especialización en la viticultura a partir del siglo xvml, las tecnologías tradicionales habian favorecido a las pequeñas explotaciones.

El impacto de las economias de escala resulta difícil de valorar en el Interior y en Andalucia, dos regiones caracterizadas por una mayor similitud de cultivos y condiciones climáticas respecto al norte y la zona mediterránea. Con anterioridad a la Segunda República, los rendimientos del trigo eran poco diferentes en Andalucia, región latifundista, que en el Interior, donde las pequeñas explotaciones eran muy comunes ${ }^{31}$. La explicación de este hecho se aborda en otra parte. No obstante, el progreso técnico en el cultivo de secano parece haber realizado tan sólo una contribución mínima al crecimiento de los rendimientos en el periodo anterior a la Guerra Civil. Por tanto, el rendimiento de los cereales y la intensidad de rotación diferían sólo de forma marginal entre las grandes y las pequeñas explotaciones. En los casos en que la tecnología condujo a incrementos en el rendimiento, por ejemplo con la introducción de razas vacunas más especializadas, de cepas resistentes a la filoxera, o mejores tipos de arroz o de naranja, los beneficiarios fueron los propietarios de pequenas explotaciones, normalmente en la periferia ${ }^{32}$.

${ }^{30}$ Las islas Canarias producian otro 7 por ciento, lo que deja tan sólo un 38 por ciento para el Interior y Andalucia.

${ }_{31}$ La Mancha y Extremadura constituyen una excepción.

32 Sin embargo, con frecuencia fueron los propietarios de grandes explotaciones en el norte y en la zona mediterránea los introductores de los avances. Véase, por ejemplo, Calatayud (1986), Garrabou y Pujol (1988) y Puente Fernández (1992). 


\section{2b. La productividad del trabajo}

Si bien las diferencias en la productividad del trabajo entre regiones son más pequeñas que la producción por hectárea, éstas son más difíciles de explicar. Mientras que el norte se considera habitualmente como una de las más «atrasadas» de Europa, estudios recientes apuntan a que la zona mediterránea fue «lider» ${ }^{33}$. Este problema exige un comentario más detallado.

En primer lugar, la cifra relativamente alta para el norte se puede explicar en parte por las distorsiones motivadas por incluir únicamente el trabajo masculino y el supuesto de que el número de horas trabajadas es el mismo que en otras regiones. Claramente, ésta no era la situación. El norte era, sin lugar a dudas, la región en la que el trabajo femenino desempeñaba el papel más importante en la agricultura, ya que sustituía durante amplios periodos temporales a los varones que habian emigrado en busca de ingresos monetarios. Si suponemos que la población activa femenina equivalía a dos tercios de la masculina en el norte y a un tercio en el resto del país, entonces la productividad del trabajo en el norte hubiera sido el 82 por ciento de la zona mediterránea, el 95 por ciento del Interior aunque un tercio más que en Andalucia. Sin embargo, esta argumentación es peligrosa no sólo por la naturaleza de las hipótesis empleadas, sino porque no se aborda un problema de gran importancia, a saber, el del nivel de vida. La productividad del trabajo no se puede considerar un indicador directo de la renta per cápita porque no tiene en cuenta los gastos de explotación del campesino, los impuestos o las rentas existentes. Sin embargo, parece ser que los agricultores norteños proporcionaban ellos mismos la mayor parte de los insumos de factores, no resulta probable que los pagos por impuestos fueran considerablemente mayores que en el resto del país y se fueron convirtiendo poco a poco en propietarios de la tierra ${ }^{34}$. Quizá todavía más importante, los agricultores norteños parecen haberse beneficiado tanto de una productividad del trabajo elevada en la agricultura como de los ingresos derivados de las migraciones de carácter estacional (además de las remesas de emigrantes). En vez de ser una de las regiones más pobres del pais, el norte parece ser una de las más ricas. Los observadores coetáneos hacen que este argumento no resulte convincente, por lo que es preciso acudir a otras fuentes.

Una posibilidad que hay que descartar es que los coeficientes empleados o el uso de índices de precios nacionales, en vez de provinciales, hayan produci-

\footnotetext{
${ }^{33}$ En particular, Garrabou (1985).

34 Sin embargo, la existencia de minifundios y la falta de oportunidades de empleo alternativas en la región probablemente empujó al alza el precio de la tierra. No existe información para calcular la importancia sobre la rentabilidad de las explotaciones.
} 
do sesgos considerables. Si seguimos el método utilizado por el GEHR (es decir, utilizando la producción total y no la final) no se modifica de forma significativa la posición relativa del norte ${ }^{35}$. De la misma forma, estimaciones anteriores de la producción final utilizando series de precios provinciales, en vez de nacionales, tampoco modificaban de forma apreciable la elevada productividad del trabajo del norte ${ }^{36}$.

La respuesta a este problema puede encontrarse en las series de precios. El norte era una región de minifundios y malas comunicaciones tanto con el interior como con el resto del país. Si desde una fecha temprana el trabajo se encontraba integrado en los mercados nacionales e internacionales, no ocurría lo mismo con los mercados de productos. En una fecha tan tardía como mediados de la década de 1960, los agricultores dedicaban un tercio de la producción final al autoconsumo ${ }^{37}$. Una proporción considerable de la producción no sólo no formaba parte del mercado, sino que tampoco se intercambiaba, un hecho que las estadísticas oficiales obviamente ignoran ya que asignan un precio de mercado a toda la producción, se venda o no. Un bajo nivel de integración en los mercados de productos agrícolas limitaría de manera considerable el crecimiento económico, ya que la producción agraria excedentaria no se podría convertir de manera sencilla en riqueza almacenable ${ }^{38}$. La producción ganadera destinada al mercado hubiera podido superar esta limitación, siendo compatible con la dotación de recursos naturales de la región. Sin embargo, el reducido tamaño de la mayoría de las explotaciones hacia que la especialización llevara asociados riesgos considerables y la mayoría de los agricultores no tenían ni los recursos necesarios ni acceso a los mercados de capitales.

35 Las cifras sobre cultivos en 1931, junto con las estimaciones de la ganadería que empleamos en este trabajo, apuntan a que la productividad del trabajo en el norte era un tercio superior a la media nacional, por tanto, por encima del cuadro 5 , como seria de esperar por la doble contabilidad.

36 La productividad del trabajo era un cuarto superior a la media nacional. Simpson (1992a), cuadro 4.3. Hay un error en el cuadro 4.3 de este artículo porque la leyenda ha sido cambiada con la del cuadro 4.4.

37 Si se incluyen los reempleos, el autoconsumo alcanza un quinto. Sólo aproximadamente dos quintos de la producción total se vendia a consumidores no a agricultores. INE (1964) citado en Leal et al. (1975), p. 100.

${ }_{38}$ Mokyr (1985) utiliza este argumento para Irlanda como una explicación de que una población relativamente bien alimentada pudiera sufrir la pérdida de un millón de personas en la hambruna de $1845-1850$. 
Las dificultades para vender los productos agricolas en el norte se pueden ilustrar con los comentarios sobre la dieta de los agricultores en Guipúzcoa a finales del siglo XIX ${ }^{39}$.

«El labrador guipuzcoano, frugal cual ninguno, se alimenta de castañas, judías, un especie de torta de harina de maíz llamada tálua, carne (muy pocas veces) y principalmente de la leche de sus vacas; expendiéndola excedente si la finca se halla próxima á un centro de consumo ó en determinados casos confeccionando la manteca y el queso para su aprovechamiento.»

A pesar de la pobreza de la dieta, en esta provincia se daba la productividad del trabajo más alta de toda España en 1909-1913. Mientras el consumo de leche fue considerado un lujo en las ciudades principales del pais, la mayoria de los agricultores del norte tuvieron problemas de encontrar mercados para su producción ${ }^{40}$.

Igual que sería erróneo olvidar que en algunas zonas del norte existían mercados eficientes para productos agricolas antes de la Guerra Civil, también sería erróneo suponer que todos los agricultores de la zona mediterránea destinaban su producción al mercado. No obstante, existian diferencias notables entre las regiones en lo que a las oportunidades se refiere: en la costa mediterránea el elevado crecimiento demográfico urbano y el dinamismo de los mercados exteriores fomentaba un elevado insumo de trabajo y capital para la producción de productos agrarios especializados, mientras que en el norte existia una «concentración de tipo Boserup en cultivos alimenticios básicos como respuesta a presiones demográficas localizadas» ${ }^{41}$. La proporción relativamente reducida de la producción nacional que hemos estimado para la zona mediterránea en 1929-1933 oculta el hecho de que una proporción mucho más elevada entra en los circuitos comerciales, lo que incrementa el valor de las industrias de transporte y de elaboración de alimentos ${ }^{42}$.

En el caso de Andalucía, la baja productividad del trabajo se puede explicar por la concurrencia de tres factores: la baja producción por hectárea, la baja ratio tierra trabajo y la falta de mecanización. Los latifundios y los bajos rendimientos no hubieran provocado una productividad del trabajo reducida si

${ }^{39}$ Dirección General de Agricultura, Industria y Comercio, Madrid (1892), 1, p. 448. Véase el Apéndice 2 sobre la productividad del trabajo.

40 Ibid., p. 448.

41 La cita es de Grantham (1989), p. 50, que realiza una distinción parecida para el norte de Francia para explicar las diferencias regionales en los ingresos agrarios por hectarrea. Véase también Parker (1982), pp. 1-24.

42 Nadal (1990), pp. 296-314; Martinez Carrión (1989), pp. 619-649; Palafox (1985), pp. 319. 343; Pérez Picazo (1990), pp. 315-341, y Simpson (1992a), pp. 131-137. 
hubieran estado asociados a un proceso de mecanización. No obstante, como indica el cuadro 6, el número de hectáreas por trabajador varón en Andalucía no era significativamente superior al de la zona mediterránea. En absoluto contraste con el norte, y especialmente Galicia, parece que mientras que los campesinos andaluces se encontraban integrados en los mercados de materias primas desde una fecha temprana, esto no era así con el trabajo ${ }^{43}$. A pesar de los reducidos salarios y una temporada laboral reducida esta región fue la única que conservó un crecimiento en el número de agricultores durante el primer tercio del siglo $\mathrm{xx}^{44}$. Si bien pocas personas dudarian de la rentabilidad de los latifundios del sur español en este período, la lentitud en el proceso de mecanización y la tardanza de la población en abandonar el campo tuvieron importantes implicaciones sobre la eficiencia global de la economía.

La última región, la Interior, comprendía tres quintos de las tierras de uso agrario de la nación y dos quintos de los trabajadores con anterioridad a la Guerra Civil. La producción por hectárea era dos tercios de la media nacional, siendo la productividad del trabajo similar a la media nacional. Aunque la zona interior presenta grandes contrastes, una característica común es la especialización en la rotación de cultivos de cereales y leguminosas. En 1929-33 estos productos representaba un 41 por ciento de la producción final, solamente el 22 por ciento los productos ganaderos y el 24 por ciento las frutas, hortalizas y plantas industriales, productos que habian contribuido a la elevada producción por hectárea en el norte y la zona mediterránea, respectivamente. La especialización en cultivos extensivos de cereales, unido a la viticultura extensiva en La Mancha y la ganadería en Extremadura, limitaban la productividad del trabajo, ya que, aunque cada agricultor tenía acceso a un terreno mayor que en el norte, dos veces y media que en la zona mediterránea y el doble que en Andalucía, los rendimientos eran significativamente menores a las de las dos primeras regiones. A pesar de la pérdida del 17 por ciento de la población activa entre 1900 y 1930, esto no fue suficiente para cerrar la brecha existente con el norte o la zona mediterránea.

\section{CAMBIOS A LARGO PLAZO EN LA PRODUCTIVIDAD REGIONAL}

En la primera parte de este artículo observamos que la productividad comenzó a crecer en el período inmediatamente anterior a la Primera Guerra

43 Véase Bernal (1988) y Herr (1989).

44 Bernal (1985), p. 246, y Simpson (1992b). 


\section{CUADRO 7}

Crecimiento de la productividad regional, 1909-1913 y 1929-1933

\begin{tabular}{|c|c|c|c|c|c|c|}
\hline & \multicolumn{2}{|c|}{$\begin{array}{c}\text { Pesetas } \\
\text { por hectarea }\end{array}$} & \multirow{2}{*}{$\begin{array}{c}\% \\
\text { cambio }\end{array}$} & \multicolumn{2}{|c|}{$\begin{array}{c}\text { Pesetas } \\
\text { por trabajador }\end{array}$} & \multirow{2}{*}{$\begin{array}{c}\% \\
\text { cambio }\end{array}$} \\
\hline & $1909 / 13$ & $1929 / 33$ & & $1909 / 13$ & $1929 / 33$ & \\
\hline \multicolumn{7}{|l|}{ Utilizando precios de 1909-1913 } \\
\hline Norte ......... & 285 & 461 & 61,8 & 774 & 1.565 & 102,2 \\
\hline Mediterránea ................ & 290 & 348 & 20,0 & 747 & 1.439 & 92,6 \\
\hline Interior $\ldots \ldots \ldots \ldots \ldots \ldots$ & 112 & 121 & 8,0 & 806 & 1.298 & 61,0 \\
\hline Andalucia $\ldots \ldots \ldots \ldots \ldots \ldots$ & 149 & 169 & 13,4 & 764 & 955 & 25,0 \\
\hline España * ................... & 155 & 182 & 17,4 & 778 & 1.286 & 65,3 \\
\hline \multicolumn{7}{|l|}{ Utilizando precios de 1929-1933 } \\
\hline Norte ........... & 531 & 809 & 52,4 & 1.440 & 2.750 & 91,0 \\
\hline Mediterránea . & 521 & 650 & 24,8 & 1.340 & 2.688 & 100,6 \\
\hline Interior $\ldots \ldots \ldots \ldots \ldots \ldots \ldots$ & 201 & 216 & 7,5 & 1.446 & 2.326 & 60,9 \\
\hline Andalucia $\ldots \ldots \ldots \ldots \ldots$ & 257 & 288 & 12,1 & 1.314 & 1.630 & 24,0 \\
\hline \multirow[t]{2}{*}{ España * } & 280 & 327 & 16,8 & 1.400 & 2.315 & 65,4 \\
\hline & & & $\begin{array}{l}\text { \% cambio } \\
\text { en la superficie } \\
\text { cultivada }\end{array}$ & \multicolumn{2}{|c|}{$\begin{array}{l}\% \text { cambio } \\
\text { en la oferta } \\
\text { de trabajo }\end{array}$} & $\begin{array}{l}\text { \% cambio } \\
\text { en el producto } \\
\text { final }\end{array}$ \\
\hline \multicolumn{3}{|l|}{ Norte ..... } & $-7,9$ & \multicolumn{2}{|c|}{$-26,4$} & $+48,9$ \\
\hline \multicolumn{3}{|l|}{ Mediterránea } & $+16,1$ & \multicolumn{2}{|c|}{$-27,8$} & $+39,1$ \\
\hline \multicolumn{3}{|l|}{ Interior ........ } & $+19,5$ & \multicolumn{2}{|c|}{$-20,0$} & $+28,8$ \\
\hline \multicolumn{3}{|l|}{ Andalucia } & $+7,7$ & \multicolumn{2}{|c|}{$-2,6$} & $+21,8$ \\
\hline \multicolumn{3}{|l|}{ Spain $\star *$} & $+13,8$ & \multicolumn{2}{|c|}{$-19,6$} & $+32,9$ \\
\hline
\end{tabular}

* Incluye las islas Canarias. Trabajadores se refiere solamente a varones.

** Las islas Canarias están incluidas en el total. Trabajadores se refiere solamente a varones. La producción final a precios de 1909/13.

Fuente: Apéndice 2. 
Mundial. Existe suficiente información para calcular la producción final agraria por provincias durante 1909-1913, por lo que se puede realizar una comparación con el periodo 1929-1933. Aunque se ha considerado necesario modificar ligeramente los métodos de estimación, los resultados son muy similares a los de la sección 2 (cuadro 7$)^{46}$.

La comparación de los cambios entre las dos fechas permite una visión más dinámica sobre nuestros comentarios de las diferencias regionales. En primer lugar, Andalucía no sólo tenía una baja producción por hectárea y una baja productividad del trabajo en 1929-1933, sino que en ambos conceptos se iba alejando de las otras tres regiones. En particular, la productividad del trabajo creció tan sólo una cuarta parte de la experimentada en el norte y en la zona mediterránea. Como hemos mencionado anteriormente, el éxodo rural fue mucho menos pronunciado en Andalucía que en las otras regiones. Si el proceso de migración se hubiera producido en Andalucía al igual que las otras regiones y la producción agraria no se hubiera visto afectada por la migración entonces la productividad del trabajo hubiera aumentado en un 59 por ciento y no el 25 por ciento que realmente creció entre 1909-1913 y 1929-1933 (a precios de 1909-1913). Una causa significativa de la creciente agitación social en Andalucia es que mientras la región fue la más lenta a la hora de liberar trabajo, también fue la región con menor crecimiento de la producción total.

La zona Interior tuvo mucho más éxito a la hora de reducir la población activa, aunque se produjeron diferencias regionales considerables en la evolución económica. El aumentó en la producción fue consecuencia de la evolución favorable de los precios de los cereales debido a las politicas públicas y el mayor uso de fertilizantes y la mejora de los arados, que trajeron consigo la extensión de los cultivos a tierras anteriormente marginales. No obstante, como indica la prensa agraria de la década de 1920, ni la mayor extensión de terreno por trabajador ni el aumento de la productividad aliviaron a la mayoría de los pequeños agricultores. Los principales problemas regionales, el de la composición de los productos, el exceso de mano de obra y el tamaño de las granjas. Si" en 1909-1913 aproximadamente el 53,9 por ciento de la producción total se obtenia de cultivos extensivos (cereales, leguminosas y vides), las cifras para 1929-1933 se redujeron a tan sólo el 51,6 por ciento ${ }^{47}$. La proporción de fru-

46 Se destacan las diferencias en el Apéndice 2. Las estimaciones por provincia muestran una tasa de crecimiento ligeramente mas reducida. Así, si bien la productividad del trabajo creció un 65 por ciento utilizando cifras nacionales, ésta creció un 59 por ciento si las cifras utilizadas eran las provinciales. La productividad de la tierra muestra un crecimiento del 21 y el 17 por ciento, respectivamente. Como apunta el cuadro 7, la utilización de precios de 1909-1913 o 1929-1933 no modifica de manera significativa los resultados.

47 Incluimos la producción vinicola, ya que la mayoria se producia en La Mancha utilizando 
tas, hortalizas y plantas industriales creció de forma marginal, pasando del 17,2 al 18,9 por ciento. Dadas las limitaciones técnicas existentes para incrementar los rendimientos en las tierras de secano, una productividad de trabajo creciente sólo podia provenir de un proceso de mecanización, lo que a su vez implicaba la emigración y la consolidación territorial.

En el caso de la zona mediterránea, la producción se incrementó aproximadamente en un 39 por ciento, mientras que los insumos del factor trabajo disminuyeron en un 28 por ciento entre las dos fechas. Los cultivos extensivos (cereales, leguminosas y vides) ${ }^{48}$ cayeron de un 34,2 a un 27,1 por ciento, pero los cultivos intensivos (a saber, arroz, frutas, hortalizas y plantas industriales) se estancaron entre el 45,8 y el 45,1 por ciento. Estas cifras son considerablemente superiores a las de cualquier otra región y son el resultado del éxito en el aumento de productos para la exportación, asi como la creciente demanda urbana de frutas y hortalizas frescas. No obstante, el incremento más importante se produjo en la ganadería, que aumentó del 14,6 al 21,8 por ciento de la producción total. Aunque la región sólo constituía el 15 por ciento de la producción nacional, en 1929-1933 la producción se incrementó en más del doble en dos décadas como respuesta a la creciente urbanización de la región ${ }^{49}$.

El caso del norte apunta un progreso significativo durante el periodo. La región no solamente expulsó aproximadamente la cuarta parte de su población activa, sino que incrementó en un 50 por ciento la producción, lo que provocó que la productividad del trabajo se duplicara. Con anterioridad a la Guerra Civil se estaban produciendo.cambios significativos en las zonas donde los agricultores se especializaban, sobre todo en el Pais Vasco y en Asturias, donde existian mercados crecientes con base en la industrialización local, y en Asturias y Santander, donde la demanda de productos ganaderos por parte de $\mathrm{Ma}$ drid creció de forma significativa desde finales del siglo xIx. En Galicia, sin embargo, la mayor fragmentación de la propiedad a finales del siglo xix y comienzos del siglo $\mathrm{xx}$, unido a las malas comunicaciones de la región, aseguraban una elevada autosuficiencia regional. Así, mientras que los crecimientos en la productividad fueron significativos tanto en Galicia como en el resto de las provincias del norte (un crecimiento del 91 y el 129 por ciento, respectivamen-

técnicas de producción extensivas (Simpson, 1992a). En 1929-1933 la producción final de la viticultura de Alava y La Rioja representaba tan sólo el 5,5 por ciento sobre el total de la zona Interior.

48 Hemos excluido el arroz de los «cultivos extensivos».

49 La producción creció un 107 por ciento en la Mediterránea entre 1909-1913 y 1929-1933 con un mayor crecimiento en Valencia (254 por ciento), Murcia (209 por ciento), Tarragona (147 por ciento), Alicante (120 por ciento) y Barcelona (104 por ciento). Para los estudios locales, véase especialmente Martínez Carrión (1991). 
te), se obtuvieron de forma diferente. En Galicia el éxodo rural fue de un modesto 16 por ciento, pero los ingresos netos por hectárea se incrementaron en un 82 por ciento; en las otras zonas, dos quintos de la población activa abandonaron la agricultura y la producción por hectárea aumentó «sólo» un 37 por ciento. En una fecha tan tardia como 1930, la población gallega con residencia en ciudades de 10.000 o más habitantes era tan sólo del 11 por ciento, frente al 32 por ciento en el resto de la zona norte o el 38 por ciento en el total nacional.

\section{CONCLUSION}

En este trabajo hemos calculado que la productividad de la mano de obra en la agricultura creció lentamente - a un 1,1 por ciento anual entre $1891 / 5$ y 1929/33. Podemos distinguir dos etapas muy diferentes: primero, entre $1891 / 5$ y 1909/13 la productividad cayó a un 0,17 por ciento anual; segundo, entre $1909 / 13$ y $1929 / 33$ hubo un fuerte crecimiento de un 2,26 por ciento anual. Desde la Guerra Civil hasta principios de la década de 1950, se produjo de nuevo una estancamiento en la productividad.

Una segunda conclusión es que el énfasis que los historiadores han puesto en la importancia regional de la agricultura ha sido acertado. El clima, los tipos de cosechas, los sistemas de cultivo, la distribución de la tierra y las oportunidades del mercado varian bastante de una región a otra. Sin embargo, la mayor parte de los recursos en la agricultura, un 81 por ciento de la tierra y un 65 por ciento de la mano de obra en 1929/33, se encontraban en las regiones del Interior y Andalucía. Debido a sus recursos naturales, estas regiones tuvieron dificultades en introducir sistemas intensivos de cultivo, y la abundancia de mano de obra en el campo hizo menos rentable la mecanización. Mientras que el Interior expulsó un 20 por ciento de su mano de obra masculina agrícola entre 1910 y 1930, en Andalucia la caida fue de menos de un 3 por ciento, lo que contribuyó a los graves problemas sociales de la êpoca. 


\section{APENDICE 1.A}

Superficie cultivada (en miles de hectáreas)

\begin{tabular}{|c|c|c|c|c|}
\hline & $1891-5$ & $1897-1901$ & $1909-13$ & $1929-33$ \\
\hline \multicolumn{5}{|l|}{ A.1. Cereales y leguminosas } \\
\hline 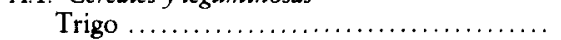 & 3.220 & 3.733 & 3.864 & 4.486 \\
\hline Cebada & 1.045 & 1.376 & 1.420 & 1.874 \\
\hline 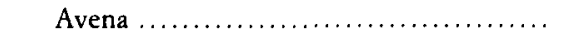 & 416 & 374 & 516 & 776 \\
\hline Centeno .............................. & 680 & 753 & 804 & 612 \\
\hline ................ & 328 & 465 & 459 & 432 \\
\hline Arroz & 32 & 34 & 38 & 48 \\
\hline Otros & 53 & 80 & 77 & 86 \\
\hline Subtotal & 5.774 & 6.815 & 7.178 & 8.314 \\
\hline Garbanzos & 145 & 167 & 180 & 232 \\
\hline Habas ..... & 158 & 211 & 183 & 207 \\
\hline ........... & 219 & 236 & 265 & 213 \\
\hline Lentejas & 16 & 15 & 17 & 25 \\
\hline Algarrobas & 69 & 87 & 152 & 205 \\
\hline Otros ..... & 78 & 77 & 129 & 271 \\
\hline Subtotal & 685 & 793 & 926 & 1.153 \\
\hline Barbecho ... & 5.292 & 6.101 & 6.247 & 6.591 \\
\hline Subtotal & 11.751 & 13.7091 & 4.351 & 16.058 \\
\hline A.2 Viñedo... & 1.460 & 1.429 & 1.274 & 1.531 \\
\hline A.3 Olivar & 1.123 & 1.197 & 1.427 & 1.952 \\
\hline \multicolumn{5}{|l|}{ A.4 Frutales } \\
\hline Naranjos & & 42 & 48 & 73 \\
\hline Almendros . & & 41 & 104 & 138 \\
\hline Algarrobos . & & 98 & 154 & 186 \\
\hline Plâtanos ............. & & & 3 & 4 \\
\hline 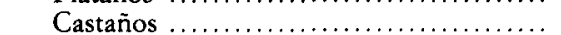 & & & 60 & 26 \\
\hline Otros .... & & 126 & 139 & 61 \\
\hline Subtotal & & 307 & 508 & 488 \\
\hline \multicolumn{5}{|l|}{ A.5 Hortalizas } \\
\hline Patatas ... & & 243 & 271 & 406 \\
\hline Cebollas. & & na & na & 27 \\
\hline (n., & & 118 & 116 & 124 \\
\hline Subtotal & & 361 & 387 & 557 \\
\hline \multicolumn{5}{|l|}{ A.6 Plantas industriales y cultivos forrajeros } \\
\hline Remolacha azucarera . & & 21 & 33 & 84 \\
\hline Cacahuetes ............ & 6 & 6 & 8 & 8 \\
\hline$\ldots \ldots \ldots \ldots \ldots \ldots \ldots \ldots \ldots$ & & 500 & 584 & 579 \\
\hline (n, & & 96 & 111 & 117 \\
\hline Otros $\ldots$ & & 61 & 83 & 235 \\
\hline Subtotal ............. & & 684 & 819 & 1.023 \\
\hline A.7 Praderas artificiales ....................... & 138 & 138 & 383 & 357 \\
\hline A.8 Pastizales & 8.274 & 8.073 & 7.683 & 6.601 \\
\hline$\ldots \ldots \ldots \ldots$ & 23.934 & 25.898 & 26.832 & 28.567 \\
\hline
\end{tabular}




\section{APENDICE $1 . B$}

Producción total agraria a precios corrientes (en millones de pesetas)

\begin{tabular}{|c|c|c|c|c|}
\hline & $1891-5$ & $1897-1901$ & $1909-13$ & $1929-33$ \\
\hline \multicolumn{5}{|l|}{ A.1 Cereales y leguminosas } \\
\hline Trigo .................. & 762 & 997 & 1.115 & 2.193 \\
\hline Cebada & 244 & 295 & 391 & 815 \\
\hline Avena .. & 65 & 60 & 92 & 220 \\
\hline Centeno $\ldots \ldots \ldots \ldots \ldots \ldots \ldots \ldots \ldots \ldots$ & 110 & 127 & 190 & 275 \\
\hline Maiz $\ldots \ldots \ldots \ldots \ldots \ldots \ldots \ldots \ldots \ldots \ldots \ldots \ldots \ldots \ldots \ldots \ldots$ & 117 & 137 & 161 & 304 \\
\hline 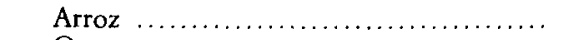 & 60 & 64 & 57 & 101 \\
\hline 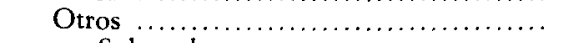 & 17 & 17 & 15 & 25 \\
\hline Subtotal & 1.375 & 1.697 & 2.021 & 3.933 \\
\hline Garbanzos . & 43 & 49 & 58 & 109 \\
\hline Habas ....... & 34 & 46 & 45 & 92 \\
\hline 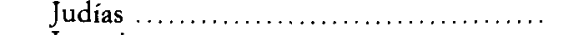 & 50 & 43 & 63 & 157 \\
\hline Lentejas & 3 & 2 & 3 & 14 \\
\hline Algarrobas . & 10 & 13 & 22 & 48 \\
\hline Otros $\ldots \ldots$ & 12 & 12 & 17 & 77 \\
\hline$\ldots \ldots \ldots \ldots \ldots$ & 152 & 165 & 208 & 497 \\
\hline Barbecho ... & 43 & 41 & 17 & 47 \\
\hline Subtotal & 1.570 & 1.903 & 2.246 & 4.477 \\
\hline A.2 Viñedo ... & 452 & 418 & 340 & 748 \\
\hline A.3 Olivar & 204 & 223 & 268 & 589 \\
\hline \multicolumn{5}{|l|}{ A.4 Frutales } \\
\hline Naranjos ... & & 51 & 69 & 252 \\
\hline Almendros. & & 25 & 49 & 108 \\
\hline Algarrobos & & 13 & 31 & 106 \\
\hline 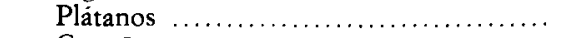 & & & 10 & 67 \\
\hline Castaños . & & & 19 & 55 \\
\hline Otros $\ldots$ & & 98 & 82 & 288 \\
\hline Subtotal & & 187 & 261 & 876 \\
\hline \multicolumn{5}{|l|}{$\begin{array}{c}\text { A.5 Hortalizas } \\
\text { Patatas .... }\end{array}$} \\
\hline $\begin{array}{l}\text { Patatas... } \\
\text { Cebollas }\end{array}$ & & 199 & 271 & 920 \\
\hline $\begin{array}{l}\text { Cebollas } \\
\text { Otros ... }\end{array}$ & & & 30 & 84 \\
\hline $\begin{array}{l}\text { Otros } \ldots \ldots . . . \\
\text { Subtotal }\end{array}$ & & 186 & 227 & 688 \\
\hline Subtotal & & 385 & 528 & 1.692 \\
\hline \multicolumn{5}{|l|}{ 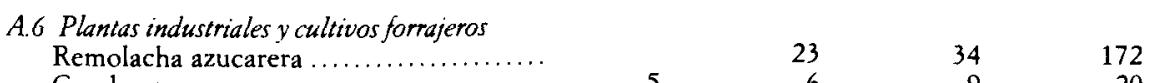 } \\
\hline $\begin{array}{l}\text { Remolacha azucarera } \ldots \ldots \ldots \ldots \ldots \ldots \\
\text { Cacahuetes } \ldots \ldots \ldots \ldots \ldots \ldots \ldots\end{array}$ & & 23 & 34 & 172 \\
\hline Cacahuetes $\ldots \ldots \ldots \ldots \ldots \ldots \ldots \ldots \ldots \ldots$ & 5 & 6 & 9 & 20 \\
\hline Esparto $\ldots \ldots \ldots \ldots \ldots \ldots \ldots \ldots \ldots \ldots \ldots \ldots \ldots \ldots$ & & 5 & 7 & 12 \\
\hline 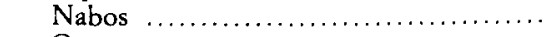 & & 22 & 40 & 85 \\
\hline Otros & & 79 & 89 & 150 \\
\hline Subtotal ........... & & 135 & 175 & 439 \\
\hline A.7 Praderas artificiales. & 66 & 82 & 156 & 319 \\
\hline A.8 Pastizales & 336 & 416 & 303 & 421 \\
\hline Total - cultivos & $\overline{72}$ & 3.749 & 4.277 & 9.561 \\
\hline - ganadería & 736 & 932 & 1.090 & 2.302 \\
\hline TOTAL - precios corrientes. & - & 4.681 & 5.367 & 11.863 \\
\hline
\end{tabular}


APENDICE 1.C

Producción total agraria a precios constantes (en millones de pesetas)

\begin{tabular}{|c|c|c|c|c|}
\hline & $1891-5$ & $1897-1901$ & $1909-13$ & $1929-33$ \\
\hline \multicolumn{5}{|l|}{ A.1 Cereales y leguminosas } \\
\hline Trigo ................. & 812 & 974 & 1.115 & 1.290 \\
\hline Cebada & 241 & 319 & 391 & 545 \\
\hline Avena... & 70 & 61 & 92 & 150 \\
\hline Centeno & 117 & 142 & 190 & 157 \\
\hline Maíz & 118 & 141 & 161 & 162 \\
\hline Arroz $\ldots \ldots \ldots \ldots \ldots$ & 42 & 46 & 57 & 78 \\
\hline Otros & 17 & 17 & 15 & 14 \\
\hline Subtotal & 1.417 & 1.700 & 2.021 & 2.396 \\
\hline Garbanzos & 50 & 57 & 58 & 68 \\
\hline Habas..... & 38 & 45 & 45 & 52 \\
\hline Judias. & 65 & 55 & 63 & 71 \\
\hline Lentejas & 6 & 4 & 3 & 5 \\
\hline Algarrobas & 9 & 11 & 22 & 25 \\
\hline Otros ....... & 13 & 13 & 17 & 40 \\
\hline Subtotal & 181 & 185 & 208 & 261 \\
\hline Barbecho ... & 14 & 17 & 17 & 18 \\
\hline Subtotal & 1.612 & 1.902 & 2.246 & 2.675 \\
\hline A.2 Viñedo. & 552 & 458 & 340 & 509 \\
\hline A.3 Olivar & 285 & 284 & 268 & 431 \\
\hline \multicolumn{5}{|l|}{ A.4 Frutales } \\
\hline Naranjos .. & & 54 & 69 & 104 \\
\hline Almendros .. & & 50 & 49 & 76 \\
\hline Otros & & 71 & 142 & 88 \\
\hline Subtotal & & 175 & 261 & 268 \\
\hline \multicolumn{5}{|l|}{ A.5 Hortalizas } \\
\hline Patatas & & 201 & 271 & 408 \\
\hline Otros & & 238 & 257 & 398 \\
\hline Subtotal & & 439 & 528 & 806 \\
\hline \multicolumn{5}{|l|}{ A.6 Plantas industriales y cultivos forrajeros } \\
\hline Remolacha azucarera $\ldots \ldots \ldots \ldots \ldots \ldots$ & & 19 & 34 & 75 \\
\hline Cacahuetes $\ldots \ldots \ldots \ldots \ldots \ldots \ldots \ldots$ & & 7 & 9 & 11 \\
\hline Esparto ... & & 6 & 7 & 7 \\
\hline (n............... & & 37 & 40 & 71 \\
\hline Otros & & 81 & 85 & 75 \\
\hline Subtotal & & 150 & 175 & 239 \\
\hline A.7 Praderas artificiales. & 56 & 56 & 156 & 145 \\
\hline A.8 Pastizales ............ & 325 & 317 & 303 & 259 \\
\hline Total - cultivos ... & - & 3.781 & 4.277 & 5.332 \\
\hline - ganadería & 953 & 891 & 1.090 & 1.426 \\
\hline TOTAL - precios constantes $\ldots . .$. & - & 4.672 & 5.367 & 6.758 \\
\hline
\end{tabular}




\section{APENDICE 1.D}

Producción final agraria a precios corrientes (en millones de pesetas)

\begin{tabular}{|c|c|c|c|c|}
\hline & $1891-5$ & $1897-1901$ & $1909-13$ & $1929-33$ \\
\hline \multicolumn{5}{|l|}{ A.1 Cereales y leguminosas } \\
\hline Trigo ................... & 498 & 720 & 808 & 1.661 \\
\hline Cebada. & 36 & 45 & 59 & 124 \\
\hline Avena & 7 & 7 & 11 & 29 \\
\hline Centeno & 88 & 102 & 133 & 188 \\
\hline Maíz............ & 52 & 61 & 73 & 135 \\
\hline Arroz $\ldots . . . .$. & 58 & 62 & 55 & 97 \\
\hline Subtotal & 739 & 997 & 1.139 & 2.234 \\
\hline$\ldots \ldots \ldots \ldots \ldots \ldots \ldots$ & 33 & 37 & 48 & 91 \\
\hline Habas.. & 4 & 5 & 5 & 11 \\
\hline Judias . & 42 & 36 & 52 & 132 \\
\hline Lentejas & 2 & 2 & 2 & 11 \\
\hline Subtotal & $8 \overline{1}$ & 80 & 107 & 245 \\
\hline A.2 Viñedo .... & 429 & 397 & 323 & 711 \\
\hline A.3 Olivar ........... & 194 & 211 & 254 & 559 \\
\hline \multicolumn{5}{|l|}{ A.4 Frutales } \\
\hline Naranjos ... & & 51 & 69 & 252 \\
\hline Almendros . & & 25 & 49 & 108 \\
\hline Plátanos ... & & & 10 & 67 \\
\hline Otros ... & & 98 & 102 & 343 \\
\hline Subtotal & & 174 & 230 & 770 \\
\hline \multicolumn{5}{|l|}{ A. 5 Hortalizas } \\
\hline Patatas ... & & 152 & 207 & 704 \\
\hline ............. & & & 30 & 84 \\
\hline 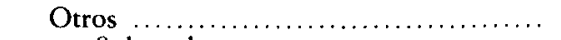 & & 186 & 227 & 688 \\
\hline 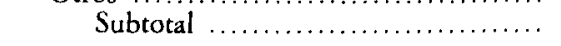 & & 338 & 464 & 1.476 \\
\hline \multicolumn{5}{|l|}{ A.6 Plantas industriales y cultivos forrajeros } \\
\hline 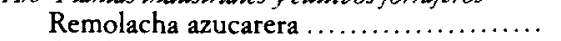 & & 23 & 34 & 172 \\
\hline Cacahuetes $\ldots \ldots \ldots \ldots \ldots \ldots \ldots \ldots \ldots$ & & 5 & 9 & 16 \\
\hline Otros & & 58 & 60 & 102 \\
\hline Subtotal & & 86 & 103 & 290 \\
\hline \multirow{2}{*}{$\begin{aligned} \text { Total } & \text { - cultivos } \\
& \text { - ganadería }\end{aligned}$} & 1.988 & 2.283 & 2.620 & 2.620 \\
\hline & 736 & 932 & 1.090 & 2.302 \\
\hline TOTAL - precios corrientes & 2.724 & 3.215 & 3.710 & 8.587 \\
\hline
\end{tabular}


A.4 Naranjos y almendros de la misma forma que A.1; para otros frutales las estimaciones se basan en el valor por hectárea de 1909/1913 (317 pta/Ha). A.5. Patatas igual que A.1; las cifras sobre plantas horticolas se basan en el valor por hectárea de $1909 / 1913(2.123 \mathrm{pts} / \mathrm{Ha})$ y la mitad del total de raíces, tubérculos y bulbos exceptuando patatas y nabos. A.6, remolacha azucarera, cacahuetes, esparto y nabos igual que A.1; se supone que las otras plantas industriales tienen la misma importancia relativa en cada período que cuando se utilizan precios corrientes; otras raices, como A.5, A.7 y A.8, se obtienen con base en el valor del producto por hectárea en 1909/ 1913. A.7 $407 \mathrm{ptas} / \mathrm{Ha}$ y $\mathrm{A} .811 \mathrm{ptas} / \mathrm{Ha}$.

\section{Apéndice 1.D}

La principal dificultad en la conversión de la producción total en producción final se refiere al empleo de coeficientes adecuados para la semilla y la proporción de reempleos. Para la semilla del trigo, la cebada, el centeno, la avena y el maíz existen estimaciones anuales para 1909/1913 (AEE año 1919, pp. 212-213). Sobre las ventas fuera del sector no existe información y se han de considerar estas estimaciones como arbitrarias. Se han empleado los siguientes coeficientes.

\begin{tabular}{|c|c|c|}
\hline & $\begin{array}{l}\text { Producción } \\
\text { total } \\
\text { semillas (\%) }\end{array}$ & $\begin{array}{l}\text { Ventas fuera } \\
\text { del sector }(\%)\end{array}$ \\
\hline Trigo & 86 & 100 \\
\hline Cebada & 88 & 20 \\
\hline Centeno & 86 & 100 \\
\hline Avena ... & 91 & 15 \\
\hline Maiz & 95 & 50 \\
\hline 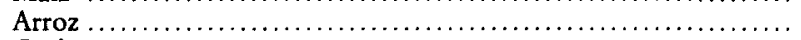 & 99 & 100 \\
\hline 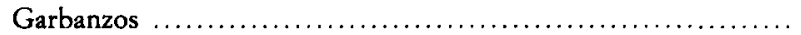 & 87 & 100 \\
\hline 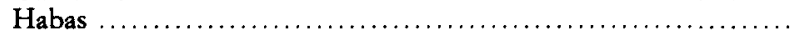 & 86 & 15 \\
\hline Judias ......... & 89 & 100 \\
\hline 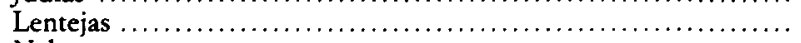 & 80 & 100 \\
\hline Nabos. & 84 & 15 \\
\hline Patatas & 90 & 85 \\
\hline
\end{tabular}

En general, hemos supuesto que para las cosechas con destino al consumo humano la totalidad de la producción de las estadisticas agrarias se refiere a ventas fuera del sector, mientras que para los cereales y las leguminosas que se asocian normalmente al consumo anual la cifra es de tan sólo el $15 \%$. En el caso de la cebada se ha considerado un $5 \%$ adicional destinado a la producción de cerveza, ya que ésta no es una industria importante en el periodo. Para el maiz, se ha empleado una cifra del $50 \%$ para las ventas fuera del sector, ya que es un producto para consumo humano y animal. Se ha supuesto que la paja, el heno y el forraje no se venden fuera del sector. Por último, los subproductos de los viñedos y olivares se supone que se consumen en el sector.

A.2 y A.3: la producción final se considera que es el 95 por ciento de la total.

A.4, A.5 y A.6: igual que en el Apéndice 1.B. Se considera que las algarrobas y los nabos se consumen en el sector.

\section{Apéndice 1.E}

Igual que los Apéndices 1.C y 1.D

\section{GANADERIA}

Precios son de GEHR (1983), p. 201. Para la producción: 


\section{Leche}

- de vaca. Los censos de 1929 y 1933 proporcionan el número de vacas dentro del total $(75$ por ciento) la proporción de vacas ordeñadas ( 45 por ciento), y ofrecen un rendimiento anual medio de 1.146 litros por cabeza. El censo de 1865 también distingue los animales según sexos ( 59 por ciento vacas) y se supone que la proporción de vacas creció de manera constante entre estas fechas. Bona ofrece un rendimiento de 730 litros por cabeza en 1877, lo que sugiere un aumento de los rendimientos y en este trabajo se supone que la tasa de crecimiento fue constante, excepto para 1865. Se utilizan los siguientes rendimientos lecheros: 1865, 700 litros; 1891/1895, 815 litros; 1897/1901, 875 litros; 1909/1913, 940 litros; 1929/1933, 1.146 litros.

- de oveja. El número de animales hembra disminuyó del 69,5 por ciento del total en 1865 a 62,7 por ciento en 1929/1933; de éste, el 23,4 por ciento se ordeñaba en esta última fecha. Los rendimientos eran de 25,8 litros por cabeza y año en $1929 / 1933$. Se supone que no hay variación en este periodo.

- de cabra. Los animales hembra descendieron desde el 73,4 por ciento del total en 1865 al 65,2 por ciento en 1929/1933. Los rendimientos al final de este periodo eran de 175 litros por cabeza, y se supone que no hay variación en este periodo.

\section{CARNE}

AEPA año 1930 proporciona:

a. el número de animales en 1929.

b. el número de animales vendidos para carne en 1930 .

c. el peso total en canal de estos animales.

d. los precios ganaderos.

A partir de estas cifras, se estima que el número total de teses sacrificadas de cada tipo en 1929/1930 era: ganado bovino, 28,0 por ciento; ganado ovino, 37,5 por ciento; ganado caprino, 38,3 por ciento, y ganado porcino, 59,6 por ciento. Se han aplicado estos coeficientes a los números totales de cada censo. En teoria, las categorias se pueden desagregar en toros, bueyes, vacas, novillos, etc. Sin embargo, probablemente las preferencias de los consumidores se modificaran durante este período (Gómez Mendoza y Simpson, 1988) y no existe forma alguna de medir estos cambios a nivel nacional.

Los pesos medios en 1930 eran de 260,5 kilos por el ganado bovino; 22,2 ganado caprino, 21,1 ganado caprino y 96,2 ganado porcino. De nuevo, a falta de evidencia empirica, no se pueden suponer cambios a largo plazo. Los precios para 1930 se extraen del censo y los referentes a otras fechas, al GEHR (1983), p. 201.

Lana. Las cifras de producción para 1929/1933 se han promediado y se han aplicado al tamaño de los rebaños de los diferentes censos. Los precios son los de lana blanca del GEHR (1983), p. 201. 
APENDICE 2.A

Producción en 1909/13 a precios de 1909/13 (en millones de pesetas)

\begin{tabular}{|c|c|c|c|c|c|c|c|c|}
\hline & Cereales & $\begin{array}{c}\text { Legumi- } \\
\text { nosas }\end{array}$ & Mosto & $\begin{array}{c}\text { Aceite } \\
\text { deoliva }\end{array}$ & Frutas & Hortalizas & $\begin{array}{c}\text { Plantas } \\
\text { industriales }\end{array}$ & $\begin{array}{c}\text { Total } \\
\text { agricola }\end{array}$ \\
\hline Alava & 6,69 & 0,15 & 0,46 & 0,02 & 0,94 & 2,44 & 0,60 & 11,32 \\
\hline Albacete & 28,27 & 0,60 & 16,17 & 3,22 & 0,50 & 6,88 & 6,34 & 62,00 \\
\hline Alicante ......... & 7,34 & 0,15 & 23,08 & 4,15 & 18,90 & 8,56 & 5.28 & 67.48 \\
\hline Almería ........ & 4,80 & 0,84 & 8,18 & 0,35 & 4,57 & 5,10 & 3,41 & 27,28 \\
\hline Avila & 16,98 & 2,73 & 6,13 & 3,15 & 1,20 & 10,02 & 0,33 & 40,56 \\
\hline Badajoz & 37,34 & 3,46 & 6,07 & 5.53 & 0,47 & 14,32 & 0,02 & 67,22 \\
\hline Baleares & 9,34 & 0,53 & 2,16 & 3,34 & 14,13 & 8,58 & 0,16 & 38,27 \\
\hline Barcelona & 11,72 & 1,12 & 44,93 & 0,43 & 0,64 & 20,21 & 0,15 & 79,22 \\
\hline Burgos & 44,82 & 2,37 & 10,03 & 0,00 & 0,64 & 26,84 & 0,43 & 85,15 \\
\hline Cáceres & 17,35 & 1,67 & 1,77 & 6,09 & 1,45 & 9,38 & 4,69 & 42,42 \\
\hline Cádiz .......... & 21,08 & 2,80 & 5,10 & 3,58 & 1,67 & 9,67 & 0,00 & 43,92 \\
\hline Canarias & 7,40 & 0,93 & 0,77 & 0,01 & 13,99 & 14,82 & 1,68 & 39,63 \\
\hline Castellón.. & 14,57 & 1,66 & 6,72 & 4,78 & 25,65 & 6,05 & 0,88 & 60,33 \\
\hline Ciudad Real .... & 14,73 & 2,01 & 17.83 & 3.61 & 0.09 & 13.68 & 0,11 & 52,08 \\
\hline Cordoba ........ & 25,44 & 3,51 & 2,36 & 39,23 & 1,44 & 8,18 & 0,00 & 80,18 \\
\hline Coruña, $\mathrm{L}_{a} . . .$. & 20,82 & 4,08 & 0,46 & 0,00 & 0,22 & 21,69 & 0,06 & 47,34 \\
\hline Cuenca .......... & 24,26 & 0,44 & 9,28 & 1,14 & 0,24 & 7,73 & 2,21 & 45,32 \\
\hline Gerona . & 15,21 & 0,61 & 3,27 & 2,60 & 0,80 & 8,77 & 0,00 & 31,28 \\
\hline Granada & 35,97 & 4,81 & 2,93 & 7,47 & 3,52 & 11,55 & 13,24 & 79,52 \\
\hline Guadalajara .... & 22,28 & 0,75 & 3,65 & 1,09 & 0,03 & 6,22 & 0,38 & 34,42 \\
\hline Guipúzcoa ...... & 4,46 & 0,61 & 0,01 & 0,00 & 6,32 & 1,74 & 0,00 & 13,16 \\
\hline Huelva .......... & 7,76 & 0,86 & 2,55 & 3,60 & 1,50 & 4,02 & 0,00 & 20,32 \\
\hline Huesca ......... & 29,85 & 1,34 & 7,08 & 3,52 & 0,61 & 9,37 & 0,13 & 51,93 \\
\hline Jaén & 35,66 & 1,68 & 1,59 & 34,19 & 0,67 & 8,05 & 0,12 & 81,99 \\
\hline$\ldots \ldots \ldots$ & 24,11 & 4,45 & 2,31 & 0,00 & 0,24 & 7,34 & 0,79 & 39.26 \\
\hline Lleida & 20,32 & 0,59 & 4,48 & 13,15 & 2,27 & 8,66 & 0,90 & 50,40 \\
\hline Lugo & 16,01 & 2,38 & 2,89 & 0,01 & 5,39 & 24,44 & 0,63 & 51,77 \\
\hline Madrid & 26,41 & 2,73 & 14,91 & 1,80 & 0,60 & 10,31 & 1,63 & 58,41 \\
\hline Málaga & 20,37 & 1,26 & 15,49 & 11,47 & 3,66 & 9,12 & 9,45 & 70,86 \\
\hline Murcia & 14,56 & 0,31 & 7,07 & 5,23 & 16,40 & 10,03 & 8,93 & 62,55 \\
\hline Navarra ........ & 31,43 & 0,87 & 3,16 & 0,44 & 0,66 & 14,60 & 1,94 & 53,14 \\
\hline Orense & 18,90 & 1,56 & 9,34 & 0,00 & 2,60 & 7,41 & 0,31 & 40,15 \\
\hline Oviedo ......... & 9,49 & 4,38 & 1,37 & 0,00 & 12,62 & 23,19 & 2,02 & 53,09 \\
\hline Palencia & 25,70 & 0,39 & 1,89 & 0,00 & 0,10 & 1,90 & 0,15 & 30,16 \\
\hline Pontevedra .... & 20,24 & 8,86 & 4,96 & 0,00 & 1,26 & 3,19 & 0,00 & 38,54 \\
\hline Rioja, $\mathrm{La}$ & 11,71 & 0,78 & 2,25 & 0,15 & 0,18 & 7,19 & 0,21 & 22,50 \\
\hline Salamanca ..... & 47,89 & 3,84 & 2,50 & 0,87 & 2,53 & 4,85 & 0,59 & 63,09 \\
\hline Santander ...... & 3,27 & 0,54 & 0,02 & 0,00 & 0,81 & 4,12 & 0,07 & 8,85 \\
\hline Segovia ......... & 16,53 & 1,43 & 1,17 & 0,00 & 0,06 & 3,56 & 0,02 & 22,78 \\
\hline Sevilla. & 57,78 & 6,55 & 5,17 & 50,50 & 3,26 & 7,12 & 0,30 & 130,70 \\
\hline Soria & 21,84 & 0,53 & 0,95 & 0,00 & 0,06 & 5,41 & 0,20 & 29.01 \\
\hline Tarragona & 16,77 & 1,34 & 30,60 & 12,84 & 21,47 & 8,81 & 0,21 & 92,06 \\
\hline Teruel ........... & 19,45 & 2,35 & 3,58 & 5,88 & 0,55 & 7,34 & 4,66 & 43,84 \\
\hline Toledo ......... & 48,96 & 3,96 & 8,15 & 4,59 & 0,46 & 7,27 & 2,91 & 76,32 \\
\hline Valencia & 77,83 & 2,18 & 24,46 & 5,73 & 38,02 & 28,52 & 9,15 & 185,91 \\
\hline Valladolid. & 36,74 & 1,72 & 5,07 & 0,00 & 0,22 & 3,13 & 1,59 & 48,49 \\
\hline Vizcaya .... & 2,48 & 0,86 & 0,13 & 0,00 & 2,63 & 2,48 & 0,00 & 8,61 \\
\hline Zamora & 31,08 & 1,22 & 6,77 & 0,02 & 1,08 & 3,38 & 1,30 & 44,87 \\
\hline Zaragoza & 40,13 & 0,91 & 6,55 & 3,88 & 3,18 & 10,39 & 10,30 & 75,36 \\
\hline ESPAÑA & $1.124,37$ & 95,89 & 348,03 & 247,80 & 220,70 & 467,83 & 98,60 & $2.603,25$ \\
\hline
\end{tabular}




\begin{tabular}{|c|c|c|c|c|c|c|c|}
\hline Janadería & $\begin{array}{l}\text { Prad } \\
\text { total }\end{array}$ & Trabajo & $\begin{array}{l}O / L M \\
\text { pesetas }\end{array}$ & $\begin{array}{c}\text { Superficte } \\
\text { total bectáreas }\end{array}$ & $\begin{array}{c}O / H \\
\text { pesetas }\end{array}$ & $\begin{array}{l}\text { Praductividad } \\
\text { del trabajo }\end{array}$ & $\begin{array}{c}\text { Productividad } \\
\text { de la tierra }\end{array}$ \\
\hline 6,24 & 17,56 & 19.716 & 890 & 76.969 & 228 & 114 & 146 \\
\hline 12,32 & 74,33 & 71.077 & 1.045 & 655.012 & 113 & 134 & 73 \\
\hline 3,29 & 70,78 & 115.318 & 613 & 287.529 & 246 & 78 & 158 \\
\hline 6,26 & 33,55 & 87.829 & 382 & 424.085 & 79 & 49 & 50 \\
\hline 17,32 & 57,89 & 57.262 & 1.011 & 436.753 & 132 & 129 & 85 \\
\hline 39,58 & 106,80 & 162.091 & 658 & 1.142 .733 & 93 & 84 & 60 \\
\hline 23,80 & 62,08 & 66.880 & 928 & 277.631 & 223 & 119 & 143 \\
\hline 19,62 & 98,84 & 159.384 & 620 & 220.829 & 447 & 79 & 288 \\
\hline 13,96 & 99,11 & 89.593 & 1.106 & 647.854 & 152 & 142 & 98 \\
\hline 26,72 & 69,14 & 110.686 & 624 & 863.793 & 80 & 80 & 51 \\
\hline 21,14 & 65,07 & 79.665 & 816 & 378.585 & 171 & 104 & 110 \\
\hline 18,62 & 58,25 & 82.648 & 704 & 248.394 & 234 & 90 & 150 \\
\hline 8,24 & 68,58 & 89.235 & 768 & 268.380 & 255 & 98 & 164 \\
\hline 10,68 & 62,77 & 90.365 & 694 & 843.598 & 74 & 89 & 47 \\
\hline 30,06 & 110,25 & 128.633 & 857 & 829.298 & 132 & 110 & 85 \\
\hline 50,39 & 97,74 & 129.338 & 755 & 605.596 & 161 & 97 & 103 \\
\hline 16,07 & 61,39 & 79.475 & 772 & 590.267 & 104 & 99 & 66 \\
\hline 20,15 & 51,43 & 68.182 & 754 & 132.271 & 388 & 96 & 250 \\
\hline 17,95 & 97,47 & 129.490 & 752 & 585.010 & 166 & 96 & 107 \\
\hline 9,10 & 43,52 & 61.052 & 712 & 423.716 & 102 & 91 & 66 \\
\hline 32,39 & 45,55 & 30.187 & 1509 & 82.371 & 553 & 193 & 355 \\
\hline 22,87 & 43,19 & 59.010 & 731 & 227.867 & 189 & 94 & 121 \\
\hline 16,00 & 67,93 & 70.525 & 963 & 648.402 & 104 & 123 & 67 \\
\hline 22,05 & 104,04 & 163.122 & 637 & 774.704 & 134 & 81 & 86 \\
\hline 23,19 & 62,46 & 106.212 & 588 & 403.772 & 154 & 75 & 99 \\
\hline 12,71 & 63,11 & 79.368 & 795 & 478.989 & 131 & 102 & 84 \\
\hline 59,16 & 110,94 & 133.406 & 831 & 198.944 & 557 & 106 & 358 \\
\hline 26,00 & 84,41 & 147.524 & 572 & 54.8817 & 153 & 73 & 98 \\
\hline 10,23 & 81,09 & 120.009 & 675 & 39.5674 & 204 & 86 & 131 \\
\hline 6,54 & 69,10 & 155.416 & 444 & 668.281 & 103 & 57 & 66 \\
\hline 24,88 & 78,02 & 77.995 & 1000 & 587.926 & 132 & 128 & 85 \\
\hline 30,82 & 70,97 & 108.167 & 656 & 149.263 & 475 & 84 & 306 \\
\hline 72,80 & 125,89 & 170.383 & 738 & 570.059 & 220 & 94 & 142 \\
\hline 8,73 & 38,89 & 49.425 & 786 & 355.608 & 109 & 101 & 70 \\
\hline 20,95 & 59,49 & 88.871 & 669 & 232.808 & 255 & 86 & 164 \\
\hline 7,27 & 29,78 & 41.233 & 722 & 375.362 & 79 & 92 & 51 \\
\hline 20,43 & 83,53 & 84.285 & 991 & 730.715 & 114 & 127 & 73 \\
\hline 35,22 & 44,07 & 52.537 & 838 & 140.036 & 314 & 107 & 202 \\
\hline 9,60 & 32,38 & 41.224 & 785 & 359.855 & 90 & 100 & 57 \\
\hline 28,86 & 159,56 & 141.419 & 1128 & 103.5934 & 154 & 145 & 99 \\
\hline 15,32 & 44,34 & 41.261 & 1074 & 303.181 & 146 & 138 & 94 \\
\hline 3,83 & 95,89 & 95.068 & 1008 & 274.958 & 348 & 129 & 224 \\
\hline 12,21 & 56,05 & 67.030 & 836 & 779.409 & 71 & 107 & 46 \\
\hline 21,79 & 98,11 & 109.561 & 895 & 876.443 & 111 & 115 & 72 \\
\hline 20,30 & 206,21 & 218.604 & 943 & 359.277 & 573 & 121 & 369 \\
\hline 12,45 & 60,95 & 61.848 & 985 & 535.587 & 113 & 126 & 73 \\
\hline 31,54 & 40,15 & 55.600 & 722 & 106.943 & 375 & 92 & 241 \\
\hline 9,76 & 54,63 & 74.508 & 733 & 515.750 & 105 & 94 & 68 \\
\hline 14,98 & 90,34 & 114.938 & 786 & 561.257 & 160 & 101 & 103 \\
\hline $1.004,61$ & $3.607,87$ & 4.636 .655 & 778 & 23.216 .495 & 155 & 100 & 100 \\
\hline
\end{tabular}




\section{APENDICE 2.B}

Producción en 1931 a precios de 1931 (en millones de pesetas)

\begin{tabular}{|c|c|c|c|c|c|c|c|c|}
\hline & Cereales & $\begin{array}{c}\text { Legumi- } \\
\text { nosas }\end{array}$ & Mosto & $\begin{array}{c}\text { Aceite } \\
\text { de oliva }\end{array}$ & Frutas & Hortalizas & $\begin{array}{c}\text { Plantas } \\
\text { industriales }\end{array}$ & $\begin{array}{c}\text { Total } \\
\text { agricola }\end{array}$ \\
\hline Alava & 15,61 & 1,04 & 2,47 & 0,15 & 1,16 & 5,70 & 3,04 & 29,19 \\
\hline Albacete ....... & 63,66 & 1,93 & 25,43 & 3,39 & 1,08 & 14,41 & 10,11 & 120,04 \\
\hline Alicante ........ & 13,97 & 0,45 & 27,55 & 7,29 & 40,27 & 36,70 & 6,55 & 132,79 \\
\hline Almeria ........ & 9,93 & 1,28 & 15,48 & 1,63 & 16,20 & 15,16 & 7,50 & 67,20 \\
\hline Avila .......... & 32,93 & 6,42 & 6,03 & 2,37 & 1,54 & 29,72 & 0,22 & 79,26 \\
\hline Badajoz ........ & 85,30 & 10,56 & 11,38 & 22,65 & 2,19 & 45,35 & 0,07 & 177,55 \\
\hline Baleares ....... & 20,37 & 4,38 & 3,49 & 3,09 & 44,72 & 22,17 & 0,79 & 99,03 \\
\hline Barcelona ...... & 26,33 & 3,92 & 90,93 & 1,80 & 16,38 & 80,48 & 0,15 & 220,02 \\
\hline Burgos ........ & 82,58 & 2,26 & 13,62 & 0,00 & 4,04 & 34,53 & 2,89 & 139,95 \\
\hline Cáceres ....... & 61,17 & 2,45 & 1,93 & 9,62 & 4,31 & 25,64 & 4,78 & 109,94 \\
\hline Cádiz ......... & 33,54 & 13,08 & 8,42 & 5,01 & 2,39 & 17,80 & 3,18 & 83,44 \\
\hline Canarias ....... & 7,13 & 2,07 & 1,71 & 0,02 & 122,71 & 40,97 & 0,51 & 175,14 \\
\hline Castellón ....... & 17,49 & 4,63 & 7,39 & 11,69 & 107,41 & 19,31 & 0,27 & 168,22 \\
\hline Ciudad Real ... & 54,23 & 1,44 & 92,68 & 14,98 & 0,18 & 27,40 & 0,40 & 191,35 \\
\hline Córdoba ...... & 58,90 & 9,23 & 4,85 & 70,72 & 4,82 & 30,01 & 1,62 & 180,18 \\
\hline Coruña, La ..... & 39,38 & 18,61 & 1,14 & 0,00 & 3,67 & 148,51 & 0,00 & 211,33 \\
\hline Cuenca ......... & 87,94 & 1,47 & 16,11 & 6,55 & 0,45 & 29,12 & 4,59 & 146,26 \\
\hline Gerona & 22,92 & 1,67 & 8,40 & 3,27 & 4,15 & 22,13 & 0,01 & 62,57 \\
\hline Granada & 71,23 & 11,21 & 3,47 & 16,19 & 11,22 & 30,70 & 47,83 & 191,88 \\
\hline Guadalajara .... & 43,68 & 1,59 & 1,30 & 4,24 & 0,28 & 18,83 & 2,17 & 72,11 \\
\hline Guipúzcoa ..... & 7,34 & 3,45 & 0,02 & 0,00 & 6,37 & 5,37 & 0,00 & 22,56 \\
\hline Huelva ......... & 16,12 & 2,19 & 14,35 & 7,34 & 8,54 & 11,88 & 0,00 & 60,43 \\
\hline Huesca ........ & 51,19 & 3,19 & 5,67 & 5,67 & 2,51 & 25,40 & 2,95 & 96,62 \\
\hline Jaén .......... & 40,26 & 2,94 & 3,44 & 129,83 & 3,25 & 26,20 & 0,76 & 206,71 \\
\hline León .......... & 66,38 & 7,01 & 15,70 & 0,00 & 19,18 & 35,75 & 12,95 & 157,00 \\
\hline Lleida .......... & 54,78 & 2,29 & 7,24 & 17,48 & 5,85 & 29,80 & 9,14 & 126,61 \\
\hline Lugo ... & 46,88 & 3,60 & 6,72 & 0,00 & 8,37 & 87,64 & 0,05 & 153,27 \\
\hline Madrid ......... & 30,32 & 2,74 & 15,37 & 5,26 & 2,03 & 30,80 & 8,68 & 95,21 \\
\hline Malaga ........ & 35,73 & 4,87 & 26,91 & 20,20 & 16,27 & 34,72 & 14,38 & 153,11 \\
\hline Murcia ......... & 33,82 & 0,78 & 18,05 & 6,11 & 52,21 & 34,24 & 11,71 & 156,95 \\
\hline Navarra ........ & 66,31 & 2,75 & 15,53 & 3,14 & 15,06 & 37,52 & 24,25 & 164,57 \\
\hline Orense $\ldots \ldots \ldots$ & 30,05 & 0,64 & 22,67 & 0,01 & 4,68 & 41,53 & 0,34 & 99,95 \\
\hline Oviedo ......... & 17,73 & 21,70 & 1,32 & 0,00 & 26,76 & 29,52 & 3,18 & 100,23 \\
\hline Palencia ....... & 58,66 & 1,33 & 1,37 & 0,00 & 2,47 & 12,73 & 2,18 & 78,76 \\
\hline Pontevedra .... & 39,77 & 9,68 & 8,35 & 0,00 & 5,35 & 14,34 & 0,04 & 77,55 \\
\hline Rioja, La ....... & 20,90 & 3,33 & 16,00 & 0,73 & 2,16 & 23,09 & 8,23 & 74,47 \\
\hline Salamanca ..... & 74,76 & 11,06 & 4,92 & 2,00 & 4,60 & 21,14 & 0,03 & 118,54 \\
\hline Santander ...... & 5,91 & 1,33 & 0,09 & 0,00 & 5,49 & 6,93 & 0,15 & 19,93 \\
\hline Segovia ......... & 65,32 & 4,75 & 4,38 & 0,00 & 0,24 & 15,39 & 0,07 & 90,17 \\
\hline Sevilla ......... & 90,42 & 8,26 & 5,86 & 63,45 & 5,44 & 22,23 & 9,05 & 204,73 \\
\hline Soria .......... & 35,74 & 0,64 & 0,84 & 0,00 & 0,41 & 13,39 & 0,80 & 51,84 \\
\hline Tarragona ...... & 43,36 & 2,47 & 55,11 & 29,67 & 21,03 & 37,20 & 0,29 & 189,15 \\
\hline Teruel ......... & 30,37 & 4,26 & 3,90 & 3,75 & 1,80 & 11,54 & 17,43 & 73,09 \\
\hline Toledo ... & 77,74 & 4,58 & 21,94 & 24,64 & 0,53 & 22,53 & 5,70 & 157,69 \\
\hline Valencia ....... & 81,23 & 13,38 & 35,48 & 15,62 & 204,34 & 126,78 & 21,04 & 497,90 \\
\hline Valladolid ....... & 74,77 & 2,26 & 9,88 & 0,00 & 0,44 & 9,92 & 9,00 & 106,29 \\
\hline Vizcaya ......... & 8,46 & 5,90 & 0,23 & 0,00 & 9,39 & 7,81 & 0,00 & 31,81 \\
\hline Zamora ....... & 63,26 & 2,66 & 17,93 & 0,04 & 1,06 & 16,68 & 0,16 & 101,82 \\
\hline Zaragoza ........ & 70,85 & 2,50 & 20,67 & 7,81 & 11,71 & 24,20 & 64,68 & 202,45 \\
\hline ESPÃ̃A $\ldots .$. & $2.186,91$ & 236,49 & 703,92 & 527,57 & 836,93 & $1.511,11$ & 324,12 & $6.327,07$ \\
\hline
\end{tabular}




\begin{tabular}{|c|c|c|c|c|c|c|c|}
\hline Ganadería & $\begin{array}{l}\text { Prod } \\
\text { total }\end{array}$ & Trabajo & $\begin{array}{l}O / L M \\
\text { pesetas }\end{array}$ & $\begin{array}{c}\text { Superficie } \\
\text { total bectáneas }\end{array}$ & $\begin{array}{c}\mathrm{O} / \mathrm{H} \\
\text { pesetas }\end{array}$ & $\begin{array}{c}\text { Productividad } \\
\text { del trabajo }\end{array}$ & $\begin{array}{c}\text { Productividad } \\
\text { de la tierra }\end{array}$ \\
\hline 11,91 & 41,11 & 17.290 & 2.377 & 79.882 & 514 & 102 & 157 \\
\hline 26,47 & 146,52 & 54.115 & 2.707 & 887.248 & 165 & 116 & 50 \\
\hline 11,32 & 144,11 & 77.082 & 1.869 & 322.783 & 446 & 80 & 136 \\
\hline 16,51 & 83,72 & 60.665 & 1.380 & 444.481 & 188 & 59 & 57 \\
\hline 49,92 & 129,18 & 39.802 & 3.245 & 461.706 & 279 & 140 & 85 \\
\hline 96,72 & 274,27 & 160.696 & 1.706 & 1.602 .047 & 171 & 73 & $\begin{array}{l}87 \\
52\end{array}$ \\
\hline 46,16 & 145,20 & 52.409 & 2.770 & 307.764 & 471 & 119 & $\begin{array}{r}52 \\
144\end{array}$ \\
\hline 62,93 & 282,95 & 100.349 & 2.819 & 260.270 & 1.087 & 121 & $\begin{array}{l}144 \\
332\end{array}$ \\
\hline 40,94 & 180,89 & 67.954 & 2.662 & 628.914 & 287 & $\begin{array}{l}121 \\
114\end{array}$ & \\
\hline 66,59 & 176,54 & 77.031 & 2.291 & 1.249 .160 & $\begin{array}{l}207 \\
141\end{array}$ & $\begin{array}{r}114 \\
98\end{array}$ & 88 \\
\hline 26,55 & 109,99 & 76.105 & 1.445 & 337.398 & 326 & & 43 \\
\hline 30,27 & 205,42 & 51.854 & 3.961 & 172.170 & 1.193 & $\begin{array}{r}62 \\
171\end{array}$ & 99 \\
\hline 17,32 & 185,54 & 78.334 & 2.368 & 287.414 & 645 & 171 & 365 \\
\hline 24,98 & 216,33 & 93.415 & 2.315 & 1.192808 & 645 & 102 & 197 \\
\hline 47,84 & 228,02 & 134.083 & 1.700 & $\begin{array}{r}1.192 .000 \\
845390\end{array}$ & 181 & 100 & 55 \\
\hline 109,83 & 321,16 & 107.869 & 2.977 & & 269 & 73 & 82 \\
\hline 27,66 & 173,93 & 81.437 & 2.135 & 424.931 & 755 & 128 & 231 \\
\hline 49,96 & 112,54 & 57.667 & $\begin{array}{l}2.139 \\
1.951\end{array}$ & 969.117 & 179 & 92 & 54 \\
\hline 33,69 & 225,58 & 140.890 & 1.951 & 160.856 & 699 & 84 & 214 \\
\hline 34,43 & 106,55 & $\begin{array}{r}140.890 \\
45.496\end{array}$ & 1.601 & 752.913 & 299 & 69 & $\begin{array}{r}214 \\
91\end{array}$ \\
\hline 72,93 & 95,50 & $\begin{array}{l}45.496 \\
24.986\end{array}$ & 2.342 & 419.299 & 254 & 101 & $\begin{array}{l}91 \\
77\end{array}$ \\
\hline 21,96 & 82,39 & $\begin{array}{l}24.986 \\
65.009\end{array}$ & 3.822 & 74.816 & 1.276 & 165 & $\begin{array}{r}77 \\
390\end{array}$ \\
\hline 14,63 & 111,25 & & 1.267 & 297.138 & 277 & 54 & $\begin{array}{r}390 \\
84\end{array}$ \\
\hline 38,41 & 245,12 & $\begin{array}{r}53.090 \\
148.941\end{array}$ & 2.095 & 681.015 & 163 & 90 & \\
\hline 26,84 & 183,85 & 148.941 & 1.645 & 883.697 & 277 & 71 & $\begin{array}{l}49 \\
84\end{array}$ \\
\hline 21,59 & 148,20 & 84.972 & 2.163 & 496.095 & 370 & 93 & $\begin{array}{r}84 \\
113\end{array}$ \\
\hline 197,73 & $\begin{array}{l}140,20 \\
351,01\end{array}$ & 77.618 & 1.909 & 451.676 & 328 & 82 & $\begin{array}{l}113 \\
100\end{array}$ \\
\hline 44,26 & $\begin{array}{l}351,01 \\
139,48\end{array}$ & 105.944 & 3.313 & 264.982 & 1.324 & 143 & $\begin{array}{l}100 \\
405\end{array}$ \\
\hline 49,41 & $\begin{array}{l}139,48 \\
202,52\end{array}$ & 44.649 & 3.123 & 411.490 & 338 & 134 & 405 \\
\hline 32,06 & $\begin{array}{l}202,52 \\
189,02\end{array}$ & 118.705 & 1.706 & 518.276 & 390 & 73 & 103 \\
\hline 37,79 & $\begin{array}{l}189,02 \\
202,36\end{array}$ & 101.192 & 1.867 & 753.316 & 250 & $\begin{array}{l}73 \\
80\end{array}$ & 119 \\
\hline 62,97 & & 72.353 & 2.796 & 694.449 & 291 & $\begin{array}{r}80 \\
120\end{array}$ & $\begin{array}{r}119 \\
76\end{array}$ \\
\hline 186,64 & 162,93 & 100.005 & 1.629 & 162.473 & 1.002 & $\begin{array}{r}120 \\
70\end{array}$ & $\begin{array}{l}16 \\
89\end{array}$ \\
\hline & 286,88 & 89.194 & 3.216 & 560.453 & 511 & $\begin{array}{r}70 \\
138\end{array}$ & $\begin{array}{r}89 \\
306\end{array}$ \\
\hline & 98,68 & 33.519 & 2.944 & 415.548 & 237 & & $\begin{array}{l}306 \\
156\end{array}$ \\
\hline 2,28 & 129,84 & 71.206 & 1.823 & 191.878 & 676 & & \\
\hline 9,06 & 83,53 & 32.753 & 2.550 & 368.992 & 226 & 78 & $\begin{array}{r}72 \\
207\end{array}$ \\
\hline 4,65 & 173,20 & 70.226 & 2.466 & 635.878 & & 110 & \\
\hline & & & $\begin{array}{l}2.461 \\
2.315\end{array}$ & $\begin{array}{r}753.484 \\
6.412 .176\end{array}$ & $\begin{array}{l}298 \\
326\end{array}$ & & \\
\hline & & & 2.315 & 26.412 .176 & 326 & & \\
\hline
\end{tabular}




\section{FUENTES DEL APENDICE 2.}

\section{PRODUCTIVIDAD REGIONAL}

La construcción de series de producción regional precisa un mayor número de cosechas para reducir las distorsiones de las cifras provinciales. Se emplean series de precios nacionales y no se ha realizado intento alguno para calcular los requerimientos de semilla a nivel provincial o para tener en cuenta posibles diferencias entre regiones de la proporcion de productos vendidos fuera del sector. En ambos casos se utilizan los resultados a nivel nacional (véase el Apéndice 1.D). Los años que se presentan más adelante se refieren a los empleados para calcular la producción fisica y, para el período $1929 / 1933$, la producción física y los precios. La información de los precios para el periodo 1909/1913 se ofrece en la sección de notas y fuentes.

\begin{tabular}{ccc|cc}
\hline Cultivo & Año & $\begin{array}{c}\text { Preciopor } \\
\text { tonelada }\end{array}$ & Año & $\begin{array}{c}\text { Preciopor } \\
\text { tonelada }\end{array}$ \\
\hline
\end{tabular}

\section{A.1 Cereales y leguminosas}

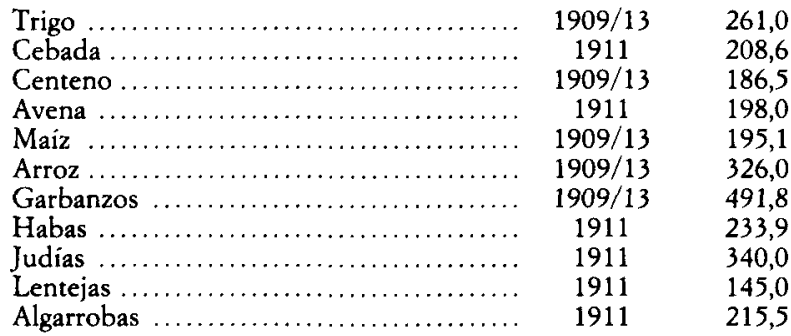

$\begin{array}{cr}1929 / 33 & 468,1 \\ 1931 & 324,1 \\ 1931 & 369,7 \\ 1931 & 284,0 \\ 1931 & 411,3 \\ 1931 & 337,2 \\ 1931 & 1.037,2 \\ 1931 & 457,0 \\ 1931 & 964,5 \\ 1931 & 856,8 \\ 1931 & 380,5\end{array}$

\section{A.2 Viñedo}

Mosto (hl) ........................... 1909/13

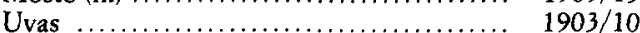

Pasas ................................... 1903/10

\begin{tabular}{c|cc}
200,0 & $1929 / 33$ & 30,1 \\
$\star \star$ & 1932 & 345,7 \\
$\star \star$ & 1932 & 100,8
\end{tabular}

\section{A.3 Olivar}

Aceite

$1909 / 13$

Aceitunas

$1903 / 10$

$1.100,0$

$1929 / 33$

$1.464,5$

1931

459,1

\section{A.4 Frutales}

Naranjas $\ldots \ldots \ldots \ldots \ldots \ldots \ldots \ldots \ldots \ldots \ldots . \ldots \ldots$

Almendros

Manzanas ...

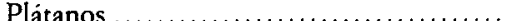

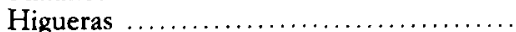

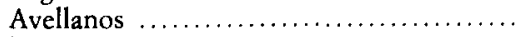

Peras ..................................

Coeficiente para otras frutas

82.5
495,5
82,0
104,1
144,5
103,0
477,4
132,8
$x 1,13$

$1929 / 33$

210.6

1931

1931

1931

985,5

393,2

287,6

1931

512,4

1931

188,8

$1931 \quad 1.328,4$

1931

1931
472,8

$\mathrm{x} 1,19$ 


\begin{tabular}{llc|cc} 
Cultivo & Año & $\begin{array}{c}\text { Precio por } \\
\text { tonelada }\end{array}$ & Año & $\begin{array}{c}\text { Precio por } \\
\text { tonelada }\end{array}$ \\
\hline
\end{tabular}

\section{A.5 Hortalizas}

\begin{tabular}{|c|c|c|c|c|}
\hline Patatas & $1910 / 12$ & 108,5 & $1929 / 33$ & 192,3 \\
\hline $\operatorname{Ajos} \ldots \ldots \ldots \ldots \ldots \ldots \ldots \ldots \ldots \ldots \ldots$ & 1910 & 164,3 & 1931 & 444,4 \\
\hline Tomates ....... & * & * & 1931 & 187,3 \\
\hline Cebollas ..... & 1910 & 164,6 & 1931 & 164,6 \\
\hline Melones & * & * & 1931 & $3.421,1$ * \\
\hline Sandias $\ldots \ldots \ldots \ldots \ldots \ldots \ldots \ldots$ & * & * & 1931 & $3.242,4$ * \\
\hline 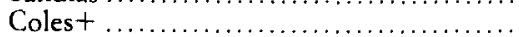 & * & * & 1931 & $5.411,0$ * \\
\hline 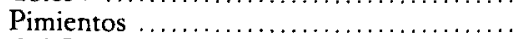 & * & * & 1931 & $6.359,3$ * \\
\hline Coliflores,$\ldots \ldots \ldots \ldots \ldots \ldots \ldots \ldots$ & * & * & 1931 & $8.023,0$ * \\
\hline Lechugas $\ldots \ldots \ldots \ldots \ldots \ldots \ldots \ldots \ldots \ldots$ & * & $\star$ & 1931 & $5.046,2$ * \\
\hline Otras hortalizas $\ldots \ldots \ldots \ldots \ldots \ldots \ldots \ldots \ldots$ & * & $1.620 *$ & 1932 & $4.060,0$ * \\
\hline
\end{tabular}

\section{A.6 Plantas industriales}

\begin{tabular}{|c|c|c|c|c|}
\hline Remolacha azucarera & 1910 & 35,6 & 1931 & 80,5 \\
\hline Caña de azucar $\ldots \ldots \ldots \ldots \ldots \ldots \ldots$ & 1910 & 40,8 & 1931 & 48,6 \\
\hline Cáñamo $\ldots \ldots \ldots \ldots \ldots \ldots \ldots \ldots \ldots$ & 1910 & $1.144,1$ & 1931 & $1.267,0$ \\
\hline Lino $. . . \ldots \ldots \ldots . .$. & 1910 & $1.971,4$ & 1931 & $1.711,6$ \\
\hline Pimientos para pimentón & 1910 & 938,7 & 1931 & $1.559,8$ \\
\hline Tabaco $\ldots \ldots \ldots \ldots \ldots \ldots . . . . .$. & 1910 & $1.100,0$ & 1931 & $1.680,0$ \\
\hline 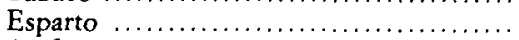 & 1910 & 12,5 * & 1931 & $17,2 *$ \\
\hline Azafran $\ldots \ldots \ldots \ldots \ldots \ldots \ldots \ldots \ldots \ldots$ & 1910 & 996,7 & 1931 & $1.843,3$ \\
\hline Cacahuetes. & 1910 & $1.151,0$ & 1931 & $2,264,9$ \\
\hline
\end{tabular}

\section{A.7 Productos ganaderos}

a. leche

\begin{tabular}{lrrr|rrr}
\hline & Census. & $\begin{array}{c}\text { Litros } \\
\text { animal }\end{array}$ & \multicolumn{1}{c|}{$\begin{array}{c}\text { Precio } \\
\text { litro }\end{array}$} & Census. & $\begin{array}{r}\text { Litros } \\
\text { animal }\end{array}$ & $\begin{array}{r}\text { Precio } \\
\text { litro }\end{array}$ \\
\hline Vaca $\ldots \ldots \ldots \ldots \ldots \ldots \ldots \ldots$ & 1917 & 1.139 & 0,31 & $1929+33$ & 1.142 & 0,45 \\
Oveja $\ldots \ldots \ldots \ldots \ldots \ldots \ldots$ & 1917 & 24 & 0,36 & $1929+33$ & 26 & 0,51 \\
Cabra $\ldots \ldots \ldots \ldots \ldots \ldots \ldots$ & 1917 & 117 & 0,42 & $1929+33$ & 177 & 0,60
\end{tabular}

b. carne

\begin{tabular}{|c|c|c|c|c|}
\hline & Censo & $\begin{array}{c}\text { Precio vivo } \\
\text { ptas. } / \text { tn. }\end{array}$ & Censo & $\begin{array}{c}\text { Precio vivo } \\
\text { ptas./In. }\end{array}$ \\
\hline Bovino & 1917 & 930 & 1930 & 1.700 \\
\hline Oveja. & 1917 & 800 & 1930 & 1.570 \\
\hline Cabrío $\ldots \ldots \ldots \ldots \ldots \ldots \ldots \ldots \ldots \ldots \ldots \ldots \ldots \ldots \ldots \ldots \ldots$ & 1917 & 1.360 & 1930 & 1.390 \\
\hline Porcino .... & 1917 & 1.100 & 1930 & 2.270 \\
\hline
\end{tabular}


c. lana

$1909 / 13 \quad 1929 / 33$

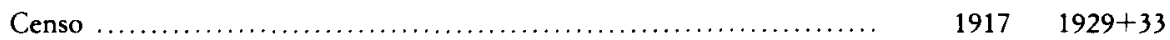

Lana por animal en kilos ......................................... $1,66 \quad 1,66$

Precio ptas. $/ \mathrm{tn} . \ldots \ldots \ldots \ldots \ldots \ldots \ldots \ldots \ldots \ldots \ldots \ldots \ldots \ldots \ldots \ldots \ldots \ldots \ldots \ldots \ldots \ldots \ldots \ldots \ldots \ldots \ldots \ldots \ldots \ldots \ldots$

\section{NOTAS}

* Existen cifras para el valor de la producción total, pero no para el volumen. En estos casos consideramos la superficie cultivada en 1931 para obtener un "precio».

** Existen cifras para el valor de la producción total, pero no para el volumen. En estos casos consideramos los rendimientos de 1931 para obtener un "precio" para 1909/1913.

+ Coles, coles de bruselas y brécol.

\section{Población activa}

Censo 1910-1930.

\section{Superficie cultivada total}

1910: Rotaciones de cereales y leguminosas, 1903/1912 (calculado por el GEHR, 1985), vides $1909 / 1913$, frutales, raices, cultivos industriales, pastos artificiales, productos de horticultura 1910 y pastos naturales 1931 (véase más adelante).

1931: AEPA, año 1931, excepto la horticultura, que hemos empleado año 1932. Los pastos na. turales incluyen praderas y dehesas, pastos y pastizales.

\section{FUENTES}

Salvo indicación en contrario, la producción en términos físicos y los precios agricolas se obtienen de las mismas fuentes que cita GEHR (1991).

\section{A.1 Cereales y leguminosas}

1909/1913: Los precios de cereales y leguminosas, excepto el arroz, se refieren al periodo $1909 / 1913$ AEE, año 1917, p. 259. Muestran la misma tendencia que Sotilla (1911) y Ministerio de Fomento, 1915 (para 1903/1912). Dado que existen diferencias significativas en el precio del arroz, preferimos Sotilla para 1909 y 1910.

\section{A.2 Viñedo}

1909/1913: Sotilla ofrece una media de 18,14 para $1903 / 1910$, pero puesto que parece que el precio es algo mayor en 1909/1913 empleamos 20 .

Uvas y pasas: Se emplean las estimaciones de 1932, ya que las estimaciones de 1931 parecen ser de escasa calidad (véase AEPA, año 1932, pp. 130-131).

\section{A.3 Olivar}

1909/1913: Precios basados en Sotilla y GEHR (1981).

Aceitunas: Se utiliza el mismo método para calcular la producción unitaria que para las uvas y pasas. 


\section{A.4 Frutales}

Se ha supuesto que las algarrobas y los higos chumbos se destinaban al consumo animal, por lo que han sido excluidos. Los precios de las frutas de la primera columna corresponden a 1905/ 1909. Se ha caiculado el coeficiente para otras frutas dividiendo el valor de los productos del cuadro anterior por el valor total de la fruta (exceptuando algarrobas e higos chumbos); esta cifra (1,13 para $1909 / 1913$ y 1,19 para $1929 / 1933)$ se aplica a los totales provinciales.

\section{A.5 Hortalizas}

Hortalizas tomadas de la rúbrica de «plantas horticolas" junto con patatas, cebollas y ajos de la rúbrica «raices, tubérculos y bulbos». El coeficiente para «otras hortalizas» se calcula dividiendo la superficie cultivada por el valor de la producción de plantas hortícolas que no se encuentran identificados en el cuadro. Para 1929/1933 utilizamos la superficie de 1932, ya que la cifra para 1931 parece cuestionable en numerosas provincias. La producción en 1910 de patatas se obtiene de BATEM, 1910, pp. 222-225.

\section{A.6 Plantas industriales}

Los precios para 1909/1913 se calculan a partir de Ministerio de Fomento (1914).

\section{A.7 Productos ganaderos}

Leche

1909/1913: Los rendimientos son provinciales. Asociación General de Ganaderos (n.d.), 1923, y precios GEHR (1983), p. 201.

Carne

1909/1913: Tamaño de la cabaña según el censo de 1917; los números y peso de los animales sacrificados igual que en 1930 (cifra nacional), el coeficiente se obtiene del AEPA, año 1930. Los precios son de GEHR (1983), p. 201.

Lana

1909/1913: Tamaño de la cabaña según el censo de 1917; Lana a nivel nacional como en 1929/1933; los precios son de GEHR (1983), p. 201.

\section{BIBLIOGRAFIA}

\section{Fuentes estadísticas generales}

AEE: Anuario Estadístico de España, Madrid.

AEPA: Ministerio de Agricultura, Anuario Estadístico de las Producciones Agrícolas, Madrid.

BATEM: Boletín de Agricultura Técnica y Economia, Madrid.

JCA: Junta Consultiva Agronómica, Madrid.

BonA, F. J. de (1877): «Producto de la leche de vaca», Gaceta Agrícola del Ministerio de Fomento, III, n. ${ }^{\circ}$, pp. 385-392. 
Dirección General de Agricultura, Industria y Comercio (1892): La ganadería en España. Avance sobre la riqueza pecuaria en 1891, formado por la Junta Consultiva Agronómica conforme a las memorias reglamentarias que en el citado año ban redactado los ingenieros del Servicio Agronómico. Madrid, 5 volúmenes.

Ministerio de Agricultura, Pesca y Alimentación (1980): Anuario de Estadística Agraria. Madrid.

Ministerio de Agricultura, Industria, Comercio y Obras Públicas. Dirección GeneRAL DE AGRICUltuRa (s.a.): Noticias estadisticas sobre la producción agrícola española por la Junta Consultiva Agronómica, 1902. Madrid.

Ministerio de Fomento. Dirección General de Agricultura, Minas y Montes (1914): Avance estadístico de la riqueza que en España representa la producción media anual de las plantas bortícolas y plantas industriales. Madrid.

- (1915): Avance estadístico de la riqueza que en España representa la producción media anual de cereales, leguminosas, vid y olivo (y) aprovechamientos diversos derivados de estos cultivos. Madrid.

Sotilla, E. de la (1911): «Producción y riqueza agrícola en España en el último decenio del siglo XIX y primero del XX», en Sanz (1981).

\section{Fuentes secundarias:}

Bernal, A. M. (1985): «La llamada crisis finisecular», en Garcia Delgado (ed.), La España de la Restauración. Madrid, Siglo XXI.

(1988): Economía e bistoria de los latifundios. Madrid, Instituto de España, EspasaCalpe.

Calatayud Giner, S. (1986): Agricultura y capitalismo. El desarrollo agrario valenciano durante la segunda mitad del siglo XIX: la Ribera del Xiquer. Universidad de Valencia, Tesis doctoral inédita.

Carmona Badia, X., y De la Puente, L. (1988): «Crisis agraria y vías de evolución ganadera en Galicia y Cantabria», en Garrabou (ed.), 1988, pp. 181-211.

Gallego, D. (1986): La producción agraria de Alava, Navarra y La Rioja desde mediados del siglo XIX a 1935. Universidad Complutense de Madrid, Tesis doctoral.

Garrabou, R. (1985): Un fals dilema. Modernitat o endarreriment de l'agricultura valenciana (1850-1900). Valencia, Institució Alfons el Magnànim.

GaRRABOU, R. (ed) (1988): La crisis agraria de fines del siglo XIX. Barcelona, Editorial Critica.

Garrabou, R., y Pujol, J. (1988): «La especialización de la agricultura mediterránea y la crisis. Cataluña y el Pais Valenciano», en Garrabou (ed.), 1988.

GarRabou, R., y SANZ, J. (1985): «Introducción», Historia agraria de la España contemporánea. 2. Expansión y crisis (1850-1900). Barcelona, Editorial Critica.

Gómez MendozA, A., y Simpson, J. (1988): «El consumo de carne en Madrid durante el primer tercio del siglo XX", Moneda y Crédito, n. ${ }^{\circ} 186$, pp. 57-91.

GRANTHAM, G. (1989): «Agricultural supply during the industrial revolution: French evidence and European implications», Journal of Economic History, vol. XLIX, pp. 43-72.

Grupo de Estudios de Historia RuRal (GEHR), (1978-79): «Contribución al análisis histórico de la ganadería española, 1865-1929», Agricultura y sociedad, vol. 8, pp. 129-182, y vol. 10, pp. 105-169. 
(1981): Los precios del aceite de oliva en España, 1891-1916. Madrid, Banco de España.

___ (1983): «Notas sobre la producción agraria española, 1891-1931», Revista de Historia Económica, vol. 1, n. ${ }^{\circ} 2$, pp. 185-252.

(1983a): «Evolución de la superficie cultivada de cereales y leguminosas en España, 1886-1935", Agricultura y Sociedad, n. ${ }^{\circ} 29$, pp. 285-325.

— (1991): Estadística bistórica de la producción agraria española, 1859-1935. Madrid, Ministerio de Agricultura, Pesca y Alimentación.

HERR, R. (1989): Rural Change and Royal Finances in Spain at the End of the Old Regime. Berkeley y Los Angeles, University of California Press.

LeAl, J. L.; Leguina, J.; NAREdo, J. M., y TARRAFeTA, L. (1977): La agricultura en el desarrollo capitalista español (1940-1979). Madrid, Siglo XXI.

Luna Rodrigo, G. (1988): «La población urbana en España», Boletín de la Asociación de la Demografía Histórica, vol. VI, n. ${ }^{\circ} 1$, pp. 25-68.

Martinez CaRrión, J. M. (1989): «Formación y desarrollo de la industria de conservas vegetales en España, 1850-1935», Revista de Historia Económica, vol. VII, n. ${ }^{\circ} 3$, pp. 619-649.

- (1991): La ganadería en la economía murciana contemporánea, 1860-1936. Murcia, Comunidad Autónoma de la Región de Murcia.

Mokyr, J. (1985): Why Ireland Starved: A Quantitative and Analytical History of the Irish Economy. Londres, George Allen \& Unwin.

NADAL, J. (1990): «El desarrollo de la economía valenciana en la segunda mitad del siglo XIX: ¿una vía exclusivamente agraria?», en Nadal y Carreras (eds.), Pautas regionales de la industrialización española (siglos XIX y XX), Barcelona, Ariel.

Nicolau, R. (1989): «Población», en Carreras, A. (ed.), Estadísticas históricas de España siglos XlX-XX, Barcelona, Fundación Banco Exterior.

PalafoX, J. (1985): «Exportaciones, demanda interior y crecimiento económico en el País Valenciano", en Sánchez-Albornoz, La modernización económica de España. Madrid, Alianza, pp. 319-343.

PARKER, W. (1982): «Opportunity sequences in European History», en Kindleberger y DiTella (eds.), Economics in the Long View, Essays in Honour of W. W. Rostow. Londres, vol. 2, pp. 1.24,

Persson, K. G. (1991): «Labour productivity in medieval agriculture: Tuscany and the 'Low Countries'" en Campbell y Overton (ed.), Land, Labour and livestock: bistorical studies in European agricultural productivity. Manchester, University Press.

Pérez Moreda, V. (1985): «La modernización demográfica, 1800-1930. Sus limitaciones y cronologia», en Sánchez-Albornoz (ed.), La modernización económica de España. Madrid, Alianza, pp. 25-62.

Pérez Picazo, M. T. (1990): «Pautas de industrialización de la región murciana. Del textil al agroalimentario», en Nadal y Carreras, Pautas regionales de la industrialización española (siglos XIX y XX). Barcelona, Ariel.

PIQUeRAs, J. (1985): La agricultura valenciana de exportación y su formación bistórica. Madrid, Instituto de Estudios Agrarios, Pesqueros y Alimentos.

PRAdos de la Escosura, L. (1988): De imperio a nación. Crecimiento y atraso económico en España (1780-1930). Madrid, Alianza.

Puente Fernandez, L. DE la (1992): Transformaciones agrarias en Cantabria, 1860-1930. Santander, Universidad de Cantabria. 
Reher, S. D. (1989): «Urban growth and population development in Spain, 1787-1930», en Lee, W. R. y Lawton, R. (eds.), Comparative Urban Population Development in Western Europe, Liverpool.

SANZ, J. (1981): «Notas introductorias al libro de Eduardo de la Sotilla: Producción y riqueza agrícola de España en el último decenio del siglo XIx y primero del XX», Agricultura y Sociedad, n. 18, pp. 303-330.

SimpSON, J. (1989): «La producción agraria y el consumo español en el siglo XIX», Revista de Historia Económica, año VII, n. ${ }^{\circ} 2$, pp. 355-388.

- (1992a): «Los límites al crecimiento agrario en España, 1860-1936», en L. Prados de la Escosura y V. Zamagni (eds.), El desarrollo económico de la Europa del Sur, Madrid, Alianza.

(1992b): «Technical Change, Labour Absorption and Living Standards in Rural Andalucia, 1886-1936", Agricultural History, 66, n. 3, pp. 1-24.

(en preparación): «Spanish Agriculture, 1765-1965».

VILAR, P. (1962): La Catalogne dans l'Espagne moderne. Paris, 3 vols.

WRIGLEY, E. A. (1985): «Urban growth and agricultural change: England and the continent in the early modern period", Journal of Interdisciplinary History, XV, pp. 683 . 728.

ZAPATA, S. (1986): La producción agraria de Extremadura y Andalucia Occidental, 1875-1935. Universidad Complutense de Madrid, Tesis doctoral. 